\title{
OPTIMIZING THE PISTACHIO SUPPLY CHAIN AND LOGISTICS NETWORK FOR FRESNO COUNTY USING GEOGRAPHIC INFORMATION SYSTEMS NETWORK ANALYSIS METHOD
}

\section{Presented to the}

Faculty of the Agribusiness Department

California Polytechnic State University, San Luis Obispo

In Partial Fulfillment

Of the Requirements for the Degree

Masters of Science

by

Farnaz Daneshpour March 2015 
(C) 2015

Farnaz Daneshpour

ALL RIGHTS RESERVED 


\section{COMMITTEE MEMBERSHIP}

TITLE:

Optimizing the Pistachio Supply Chain and Logistics Network for

Fresno County Using Geographic Information Systems Network

Analysis Method

AUTHOR: $\quad$ Farnaz Daneshpour

DATE SUBMITTED: $\quad$ March 2015

COMMITTEE CHAIR: $\quad$ Sean Hurley, PhD Agribusiness Professor

COMMITTEE MEMBER: Lindsey Higgins, PhD Agribusiness Professor

COMMITTEE MEMBER: Russell White, Numeric and Spatial Data Specialist 


\begin{abstract}
Optimizing the Pistachio Supply Chain and Logistics Network for Fresno County Using Geographic Information Systems Network Analysis Method
\end{abstract}

\title{
Farnaz Daneshpour
}

This study aims to optimize the transportation of pistachios from orchards to processing centers in Fresno County, California to improve logistics efficiency and reduce environmental impacts. This study evaluates the current transportation situation and compared it with the case in which a new processing center is built. Also, this study evaluates transportation efficiency based on calculations of total driving distance, driving time, fuel cost, and $\mathrm{Co} 2$ emission and assesses how much of these variables will be saved if a new facility center is built. This study also explores optimal locations for pistachio cultivation, based on soil characteristics such as soil $\mathrm{pH}$, type, and drainage class and compared these locations to current pistachio orchards. The study is based on data from 52 pistachio orchards in Fresno County, 11 existing large scale processing centers in the Central Valley, the current transportation network, and soil survey data. Location allocation and closest facility analyses using Network Analysis in ESRI ArcGIS are carried out on two scenarios; first for allocation of the orchards to existing processing centers and second, reallocation of orchards considering a new processing facility in the area. A Center of Gravity model is used to determine an optimal location of the new processing facility in Fresno County. Comparing two scenarios shows that there is $41 \%$ of saving in distance, $\mathrm{Co} 2$ emission, fuel cost, and driving time in a harvesting period by considering the new processing center in Fresno County. Locating the new facility center in the area can make positive improvements towards logistics efficiency and environmental issues. 


\section{ACKNOWLEDGMENTS}

I would like to thank all the people who contributed in some way to the work described in this thesis. First and foremost, I would like to express my sincere gratitude to my academic advisor, Professor Sean Hurley, for the continuous support of my Masters study and research, for his patience, motivation, enthusiasm, and immense knowledge. His guidance helped me in all the time of research and writing of this thesis. I could have not imagined having a better advisor and mentor for my Masters study.

Additionally, I would like to thank my committee for their continued support and encouragement: Dr. Lindsey Higgins and Russell White; I offer my sincere appreciation for the learning opportunities you provided.

Last but not the least, I would like to thank my family for its constant support through the ups and downs of my academic career spiritually and financially throughout my life. 


\section{TABLE OF CONTENTS}

Page

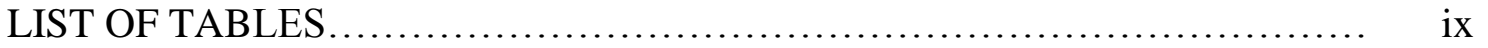

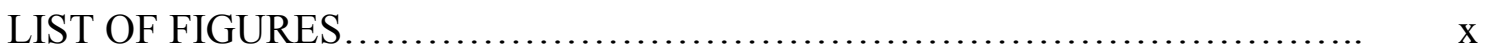

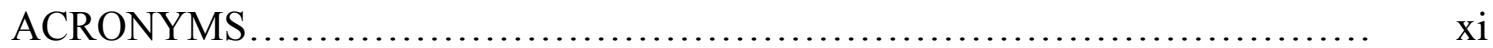

CHAPTER

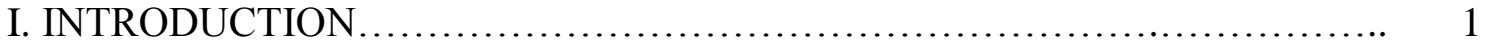

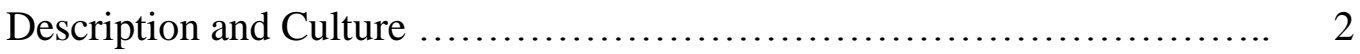

Production, Export, Import....................................... 3

Environmental Issues........................................... 6

Fresno County Overview ....................................... 9

Research Questions............................................... 10

Problem Statement............................................... 10

Hypotheses................................................ 10

Objectives..................................................... 10

Justification...................................................... 11

II. REVIEW OF THE LITERATURE....................................... 12 
Introduction.

Optimizing Transportation Using a Location Allocation Model.................... 12

III. METHODOLOGY .................................................. 19

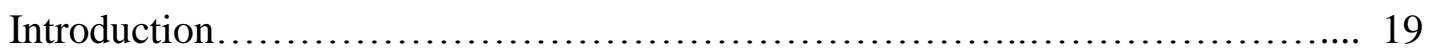

Procedures for Data Collection........................................... 19

Procedures for Data Analysis.............................................................. 21

Determination of Optimum Locations.................................... 24

Center of Gravity Technique............................................ 25

Network Analysis.................................................. 27

Network Dataset..................................................... 28

Location Allocation Model............................................. 29

Closest Facility Model............................................... 35

Calculation of Distance, Fuel Cost, Co2 Emissions, and Travel Time ............ 36

Major Assumptions for Orchards Processing Centers ...................... 40

Major Assumptions for Trucks.......................................41

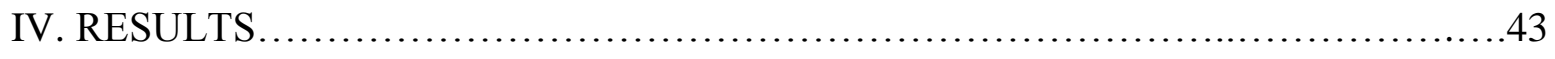

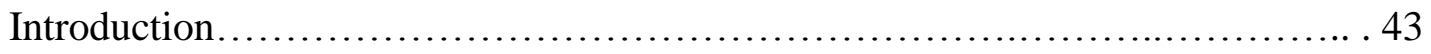

Fresno County....................................................... 43 
Determination of Optimum Locations................................... 44

Center of Gravity Model................................................ 47

Location Allocation Model............................................ 48

Closest Facility Model .................................................. 49

V. SUMMARY, CONCLUSIONS AND RECOMMENDATIONS .......................... 55

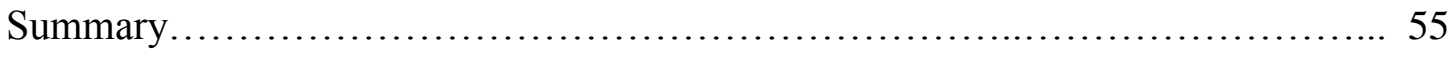

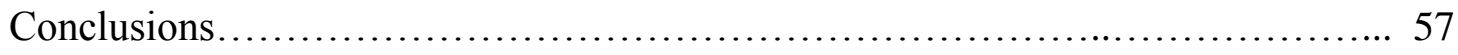

Recommendations.................................................. 59

LIST OF REFERENCES................................................... 61

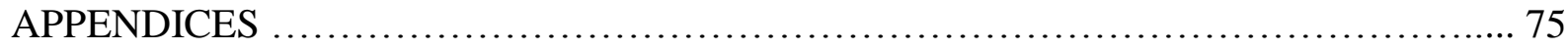

A. Processing Centers Addresses.......................................... 75

B. Center of Gravity Technique Calculation Table for all of Pistachio Orchards.... 76 


\section{LIST OF TABLES}

Table

Page

1. Location Allocation Analysis Settings for Two Scenarios..........................35

2. Closest Facility Analysis Settings for Two Scenarios................................. 36

3. Original Average Weight and Original Fuel Consumption of a Truck.................37

4. Average Weight and Fuel Consumption of a Truck ..............................37

5. Comparing Distance, Co2, Fuel Cost, and Travel Time in Scenarios 1 and 2 over a Harvesting Season for Various Speed Values-Sensitivity Analysis....................40

6. Comparing Pistachio Orchards Acreage and Production with Best Area.................46

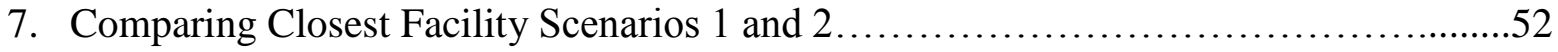

8. Comparing Distance, Co2, Fuel Cost, and Travel Time in Scenarios 1 and 2........... 54 


\section{LIST OF FIGURES}

Figure

Page

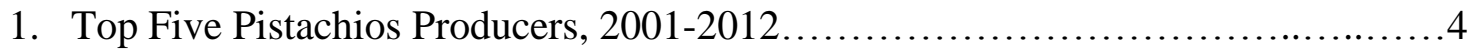

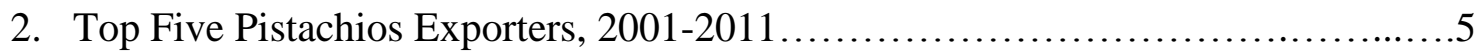

3. USA Pistachios Supply and Utilization (shelled basis), 1980-2013...............6

4. World Energy-Related Carbon Dioxide Emissions by Fuel Type in Billion Metric Tons,

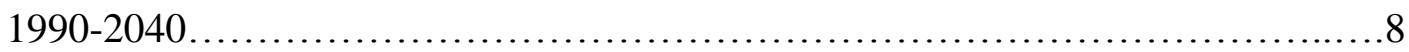

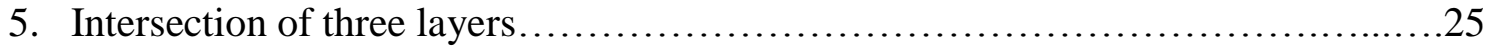

6. Creating a Network Dataset in ArcGIS ......................................28

7. Adding parameters to the Network Dataset in ArcGIS .........................29

8. California Central Valley and Fresno County....................................44

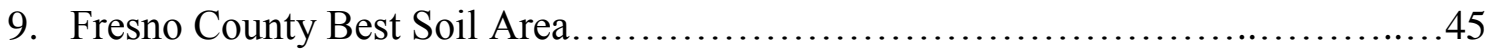

10. Fresno County Best Soil Area and Pistachio Orchards..........................46

11. New Facility Center with other Counties View...............................47

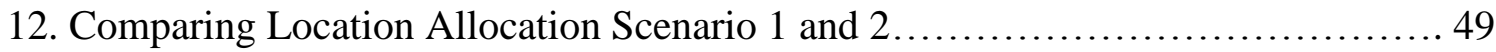

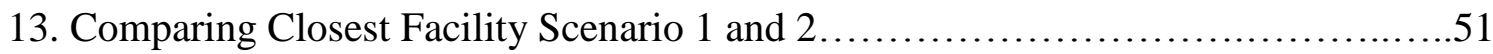




\section{ACRONYMS}

CC- Collection Centers

CDFA- California Department of Food and Agriculture

EIA-Energy Information Administration

FAO-Food and Agricultural Organization

FAS-Foreign Agricultural Service

GIS-Geographic Information Systems

HDL-High Density Lipoproteins

LDL-Low Density Lipoproteins

LSFDC-Large Scale Food Distribution Centers

MTs-Metric Tons

NASS-National Agricultural Statistics Service

NRCS- Natural Resources Conservation Service

OECD-Organization for Economic Co-operation and Development

PH-Potential of Hydrogen

USDA-United States Department of Agriculture 


\section{CHAPTER I}

\section{INTRODUCTION}

The pistachio (Pistacia Vera L., Anacardiaceae family), a member of the cashew family, is one of the oldest flowering nut trees, which originated in the Middle East and extended to the Mediterranean. They have been used from prehistoric times because of their nutritional values, disease reduction characteristics, and long storage life (Koshteh \& Urutyan, 2005). In the 1880's, pistachios were imported to the United States as a specialty nut from the Middle East. In the beginning of the early 1930s, pistachios were planted in California experimentally. Commercial production of pistachios developed throughout California's Central Valley in the 1960s and 1970s, where the long, hot summers provide ideal growing condition for proper ripening of the fruit (Koshteh \& Urutyan, 2005). Pistachio trees are now planted in countries such as Iran, Turkey, Greece, Syria, Afghanistan, China, and the United States, specifically in California (Razavi, 2005).

Pistachios are an important crop due to their economic value, high nutritious content, favorable taste, and storability. Pistachios are well-known for being a rich source of protein, minerals, mono-unsaturated fat, antioxidants, and vitamins. Pistachios are an excellent source of vitamins containing B-complex groups such as niacin, pantothenic acid, folates, riboflavin, thiamin, vitamin B-6, vitamin E, and C. Moreover, pistachios contain various minerals such as selenium, zinc, copper, calcium, magnesium, phosphorus, potassium, and iron (Kizilgoz et al., 2001). For these reasons, producing pistachios has become more common in many countries

around the world. As a commercial product and an exportable currency earning output, pistachios have an important role in agricultural production (Karim et al., 2003). 


\section{Description and Culture}

The pistachio tree is a desert tree that can survive with the full sun in a variety of soil conditions including clay, loamy, or sandy soil textures, highly alkaline soils, slightly acidic, or even saline soils (Koukoulakis et al., 2013). The best region for pistachio cultivation is a place with hot, dry climates with cool winters. However, the optimal production is on deep, friable, well drained, and sandy loam, with a soil pH slightly acidic to highly alkaline (Couceiro, et al., 2013; Demirkiran \& Cengiz, 2013). According to Sakbaeva et al. (2012), there is a direct relationship between the plant nutrient value and soil properties. In the U.S., the Central Valley in California and the Southwest of the U.S. are the best locations for pistachio cultivation because of hot, dry climates and good soil conditions (Good Agricultural Practices Manual Guidelines, 2009).

Pistachio trees are broad and bushy, with male and female flowers on separate trees. They grow slowly and require several years to begin bearing nuts, with considerable production happening at 7 to 10 years and full bearing accruing at 15 to 20 years. The pistachio tree can grow 25 to 30 feet $(10 \mathrm{~m})$ tall. Pistachios trees keep bearing nuts for centuries, although the life expectancy of commercial products is evaluated about 50 to 80 years if conditions are favorable (Ferguson et al., 2005).

There are 13 varieties of pistachios that have been cultivated in California. Kerman pistachio type is the most broadly commercial variety cultivated because it is more considered by importers and processors due to its large size, crispness, good quality, widely split shells, and favorable taste (Beede et al, 2008). Pistachio trees are like other nut trees in production variations, they have a large bearing in one year followed by a smaller production the next year. This has caused the industry to implement inventory building with large production volume to compensate for subsequent years of decreased supply. Pistachio trees are very susceptible to fungal 
contamination, which can destroy the trees and the roots quickly. In addition, the trees are sensitive to Aflatoxin contamination in all the production stage from growing, harvesting and processing. Aflatoxins, which is a toxic fungus contamination, can grow on the crop and destroy it. Drying and proper storage conditions can reduce contamination risk (CRFG, 1997).

The nuts are harvested in early fall, from September $15^{\text {th }}$ to December $10^{\text {th }}$ in California (California Fruit \& Nut Review, 2005). Pistachios grow like grape clusters. When their fleshy hull surrounding the shell and the inner shell is split and rosy hue, they are ready to be harvested. The trees are mechanically shaken and matured nuts fall down on a tarp. Then they are sent to processing centers to have their hulls removed and dried within 12 to 24 hours after harvest time, otherwise the nuts will become stained (Onay, 2005).

\section{Production, Export, and Import}

Statistics on pistachio production worldwide illustrate both the geography and recent trends in the industry. According to the United Nations Food and Agricultural Organization (FAO, 2013), world pistachio production was $1,005,436$ metric tons (MTs) in 2012. Out of the total world pistachio production, Iran produced approximately 472,097 MTs, or 47\% of world production. The United

States with a production of 231,000 MTs represents $23 \%$ of world production. Turkey with 150,000 MTs represents 15\%, while China with 74,000 MTs represents 7.3\% of world production. Figure 1 shows the top five pistachios producers in the world from 2001 to 2012 (FAO, 2013). 


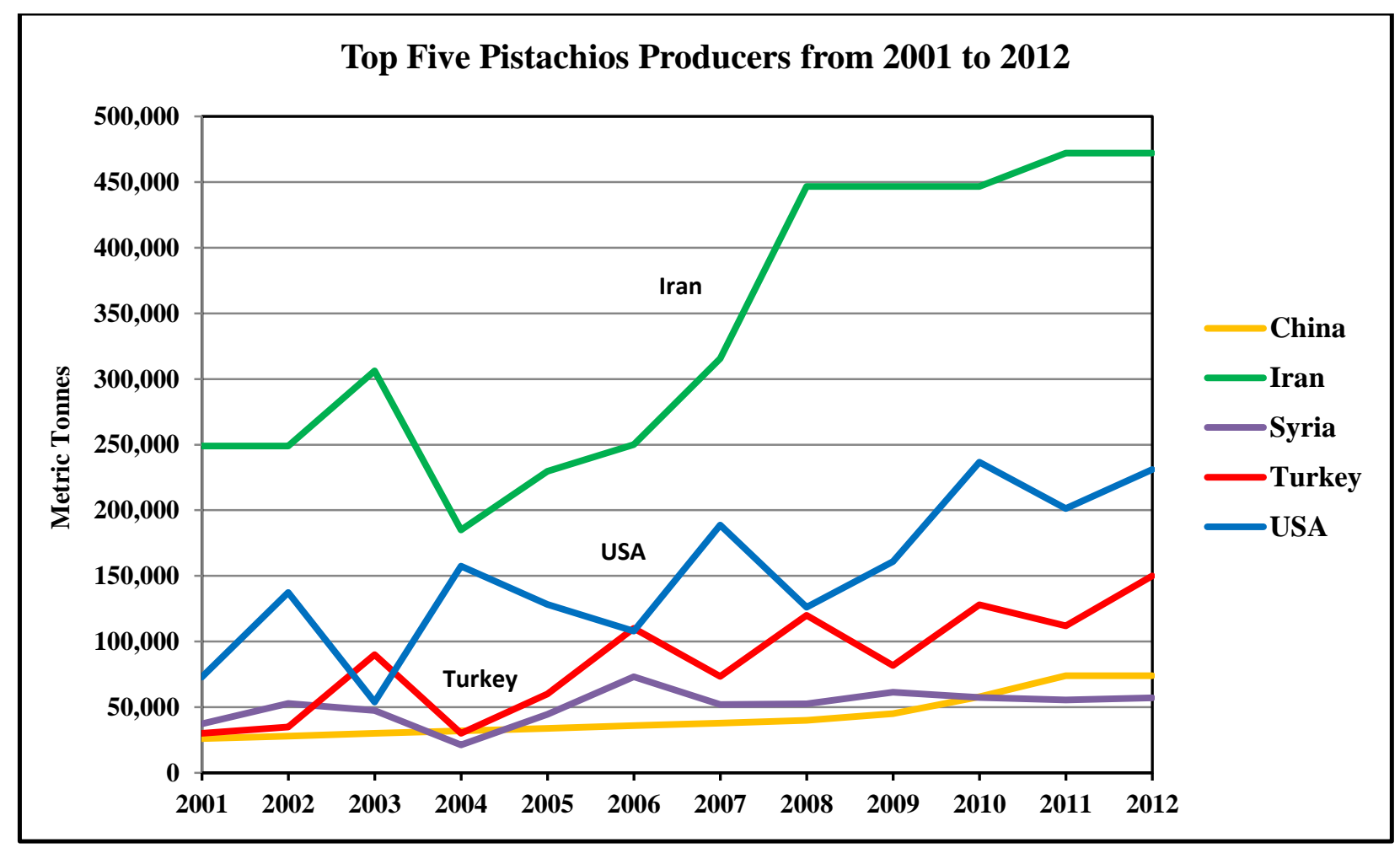

Figure 1. Top Five Pistachios Producers, 2001-2012. Source: Source: FAOSTAT, 2013.

According to National Agricultural Statistics Service (NASS, 2013), and California Department of Food and Agriculture (CDFA, 2013), U.S. pistachio production of in-shell basis ranks first in 2012 with 551.0 million pounds, or 250,000 MTs, while Iran, Syria, and Turkey produced 160,000 MTs, 65,000 MTs, and 50,000 MTs respectively. The production of pistachio nuts in the U.S. was up to $24 \%$ to 275,500 MTs because of favorable weather and a larger area of production in 2013 (FAS, 2013).

The United States Department of Agriculture (USDA, 2013) estimates approximately 222,000 tons (98\%) of U.S. pistachios production are produced in California, where the top five county producers are Kern, Fresno, Tulare, Madera, and Kings respectively. After California, other states producing pistachios include Arizona, Nevada, New Mexico, Texas and Utah.

According to the FAS (2013), the United States is the second largest pistachio exporter in the world with $24 \%$ of the total world supply. China, Syria, and Turkey are the largest pistachios 
exporters in the world after Iran and the U.S respectively (Figure 2). The most important country that the U.S. exports pistachios to is Hong Kong where the U.S. exports a total of $\$ 379.3$ million annually (FAS, 2013). The next largest country is Belgium with a value of $\$ 104.9$ million. When the nuts are exported to Hong Kong, most of the shipments are re-exported to China because the number of Chinese customers using pistachios in baked and confectionary products is increasing (Boriss, 2005). After China, the Netherlands and Canada are the most important countries for United States pistachio production. Also, pistachio nuts valued at \$1.8 Million were imported primarily from Turkey, followed by Italy and France in 2012 (Figure 2).

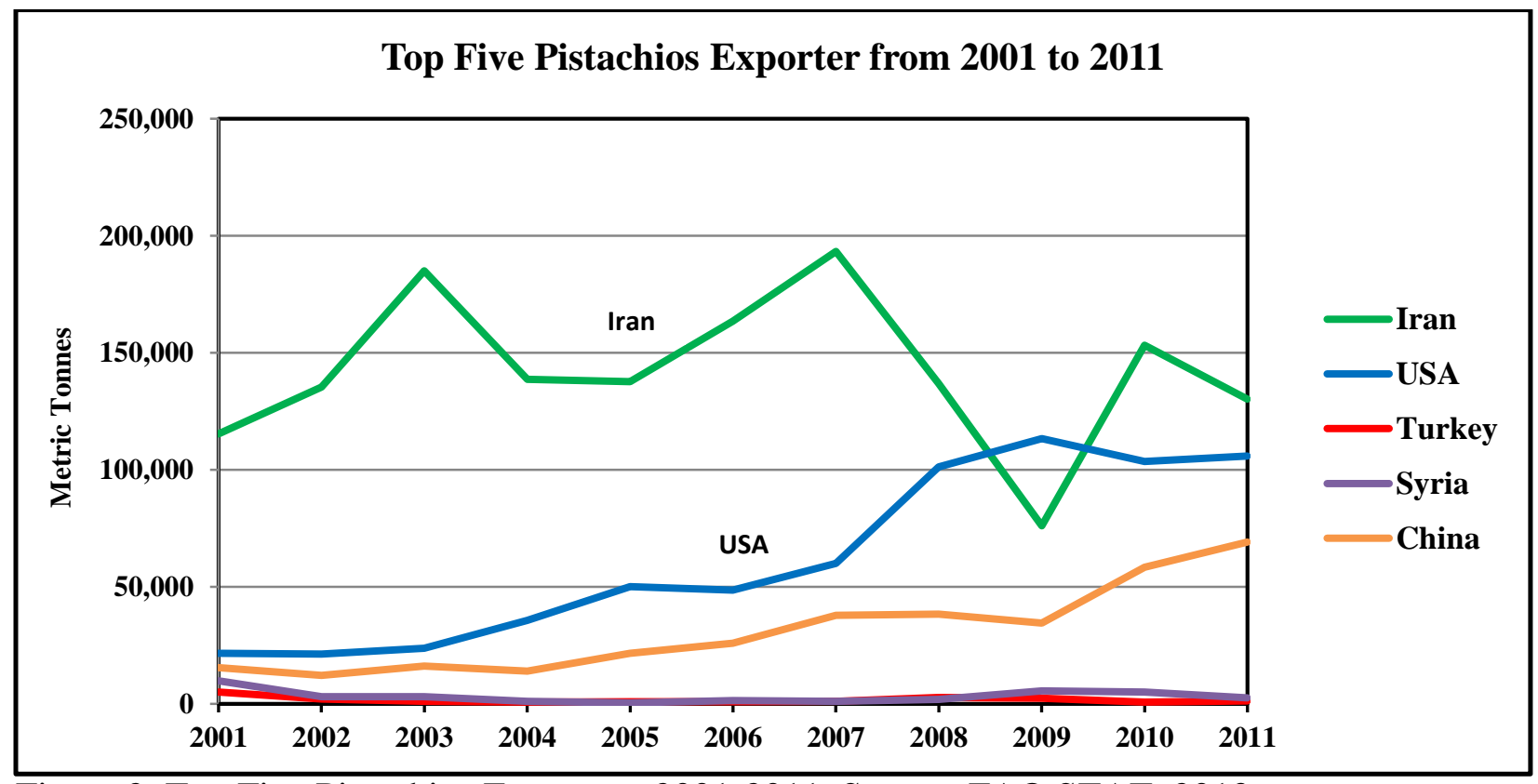

Figure 2. Top Five Pistachios Exporters, 2001-2011. Source: FAO STAT, 2013.

In Figure 3, pistachio production, consumption, and export from the U.S. are shown. Recently, domestic pistachios consumption was increased by $18 \%$ to 91,482,000 pounds in 2013 from $77,517,000$ pounds in 2012 . Also, domestic per capita consumption increased to 0.29 pounds in 2013 from 0.25 in 2012. However, domestic pistachio consumption relative to other nuts like almond, walnut, or cashew is low (USDA, 2013). 


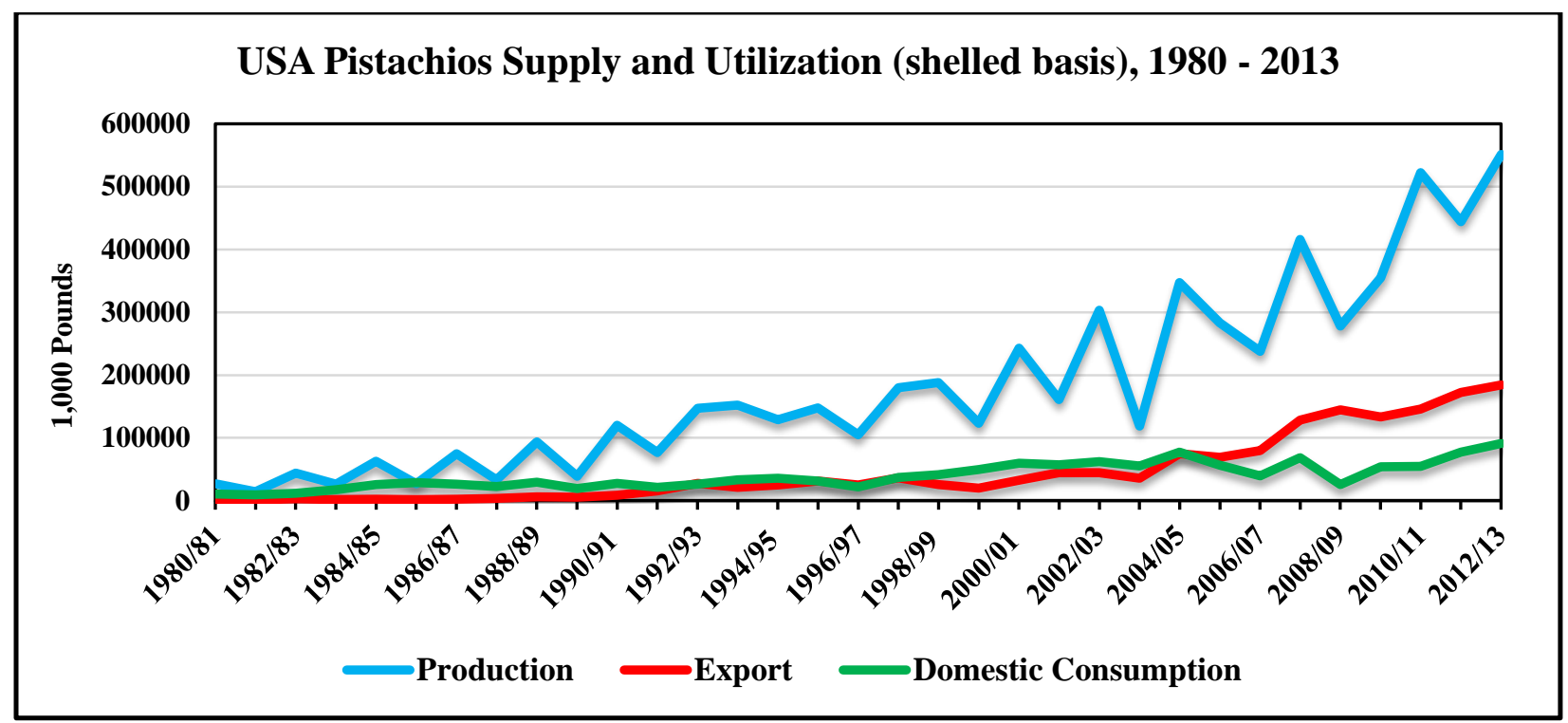

Figure 3. USA Pistachios Supply and Utilization (shelled basis), 1980 - 2013. Source: USDA, 2013.

\section{Environmental Issues}

The pistachio production has been increasing due to better use of resources, advanced technology, and more skilled labor in recent years (Zheng et al, 2012). In order to have increasing trend in pistachio production, consumption, and exportation in the long run, resources such as soil should be optimally employed. Planting on lands that are poor in nutrients, soil water capacity, soil organic materials, and soil type cause a higher rate of soil erosion which require farmers to utilize chemicals, fertilizers, and more irrigation (Ritter and Eng, 2012).

Another important environmental issue raised from increasing pistachio production is the potential increase in greenhouse gasses emissions. Soysal et al. (2014) argues that greenhouse gas emissions are believed to have grave consequences on the environment. In particular, Davis et al. (2013) believed that one of the considerable impacts on the environment comes from greenhouse gasses emissions from food transportation. Therefore, the increasing trend of food transportation around the world causes more greenhouse gasses (Davis, 2013). Rosenthal (2008) believed that the greenhouse gasses such as carbon dioxide is one of the major pollution that comes from food 
transportation. Greenhouse gasses such as carbon dioxide are the most important gasses affecting the environment (USGS, 2011). Carbon dioxide remains in the atmosphere for many millennia and threatens both environmental quality and human health. Co2 is emitted into the air when fuel is burned in the combustion process and causes the earth's temperature to increase by trapping heat in the atmosphere (CLECAT, 2010).

Consequently, energy consumption is an important cause of the global warming which affects climate change. According to U.S. Energy Information Administration (EIA, 2013), “world energy-related carbon dioxide emissions are expected to increase to 36.4 billion metric tons in 2020". As shown in Figure 4, carbon dioxide emissions from liquid fuels consumption accounted for $43 \%$ of the world total in 1990 and $36 \%$ in 2010, higher than natural fuel and lower than coal. Among the Organization for Economic Co-operation and Development (OECD) regions, the United States continues to be the largest source of energy-related carbon dioxide emissions through 2040, followed by Europe and Japan. Higher levels of energy consumption and Co2 emissions were caused by residential, commercial, and transportation sectors, which generally are more energy and carbon-intensive than other sectors of the economy (EIA, 2013).

Consequently, transportation is one of the major sources of $\mathrm{Co} 2$ emissions and pollutants. However, transportation is part of the food industry and cannot be omitted. Also, there is high dependence on fossil fuels for transportation which produces Co2 (Craiga et al, 2012). Therefore, this is the current situation of the food transportation with fossil fuel, so transportation needs to be optimized to reduce Co2 emissions. Litman (2011) argued that in the transportation segment, short mileage driving uses less fuel and produces fewer emissions. Thus, this study aims to optimize transportation by minimizing driving mileage. 


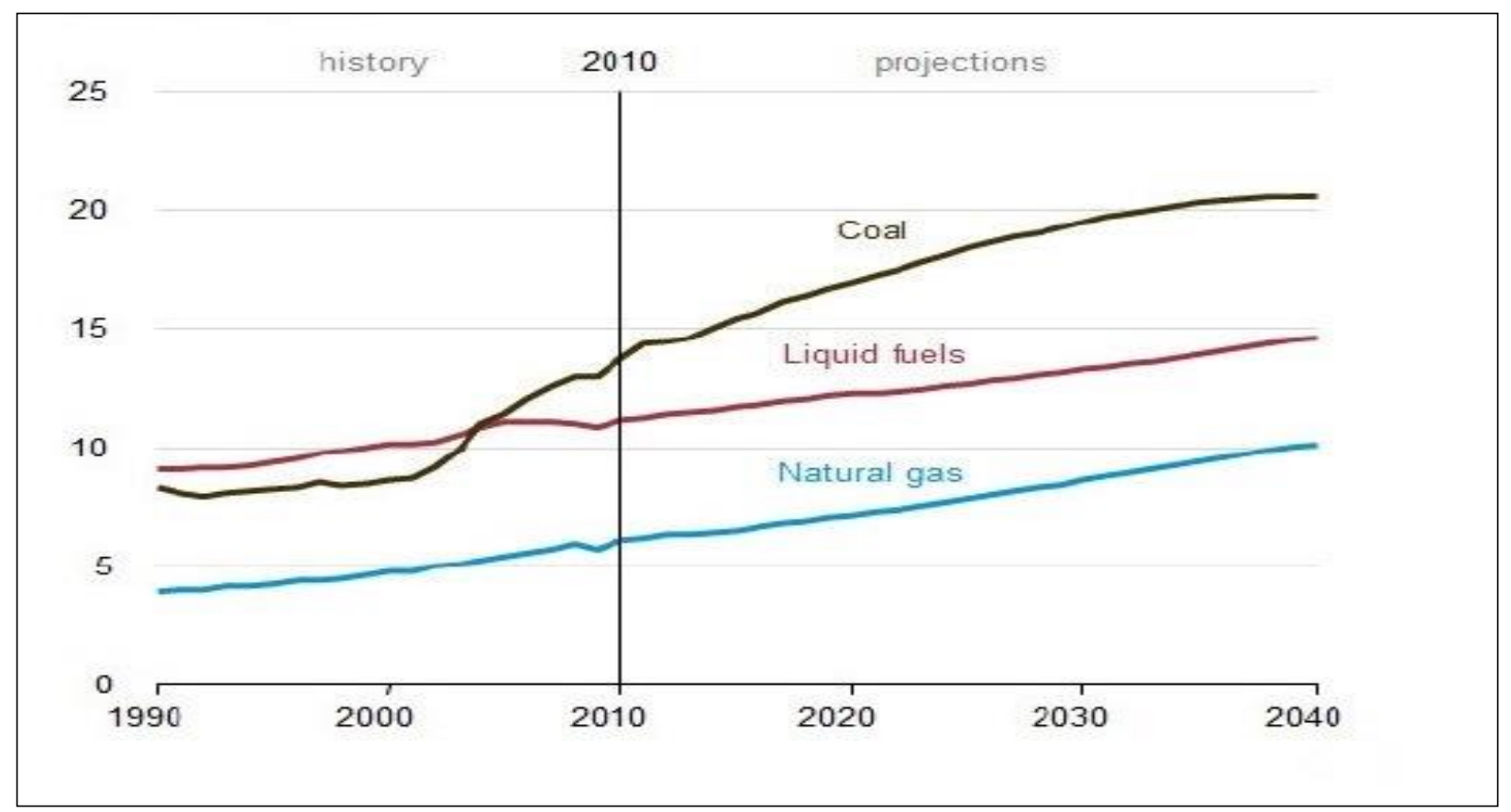

Figure 4. World Energy-Related Carbon Dioxide Emissions by Fuel Type in Billion Metrics Tons, 1990-2040.Source: U.S. Energy Information Administration, EIA, 2013.

Given the need to optimize transportation by minimizing driving mileage, Meyer (2011) believed that a facility's location could play a critical role in total transportation distance and it is necessary to find the best location for facilities. Also, pistachio cultivation should be in ideal locations to utilize soil optimally and to reduce soil erosion as well. Also, it is important to allocate the pistachio orchards to the closest facility in order to reduce shipping distance and Co2 emissions. For this aim, the location allocation model is used through Geographic Information Systems (GIS) Network Analyst extension.

ESRI ArcGIS, a GIS software, includes the Network Analyst extension, which can be used for a variety of location allocation problems. ArcGIS has a significant role in researching location allocation models (Peterson, 2009). ArcGIS is built based on spatial analyst tools that allow visualizing the output results dealing with only single objective location allocation problems and 
minimizing either time or distance (Massey, 2011). These tools and associated geospatial data for Fresno County provide the foundation for analysis in this project.

\section{Fresno County Overview}

For this study, Fresno County was selected as an objective area because of the importance of pistachio cultivation in this county and availability of the data. Also, there is only one large scale pistachio processing center located in this county. Fresno County is located in the Central Valley of California, south of Stockton and north of Bakersfield. Fresno, the fifth-largest city in California, is located in Fresno County. According to the U.S. Census Bureau in 2013, the county has a total area of 6,011 square miles $\left(15,570 \mathrm{~km}^{2}\right)$, of which 5,958 square miles $\left(15,430 \mathrm{~km}^{2}\right)$ is land and 53 square miles $\left(140 \mathrm{~km}^{2}\right)(0.9 \%)$ is water; the population was 955,272 in 2013.

Fresno County is the center of a large agricultural area, known as the most agriculturally rich county in the United States (NACo, 2013). According to the 2013 California Agricultural Statistics Review, Fresno County plays an important role in pistachio production and ranks second after Kern County in California. Fresno County accounts for $18.7 \%$ of total California pistachio harvested acreage in 2013 (CDFA, 2013). According to the 2012 Fresno County Annual Crop \& Livestock Report, pistachios’ dollar value increased by \$19,373,000 (10.97\%) from 2011 to 2012, resulting from an increase in harvested acres. In addition, production increased by $12.26 \%$ to 47,600 tons in 2012 from 42,400 tons in 2011. However, production per acre decreased by $8.5 \%$ to 1.40 tons in 2012 from 1.53 tons in 2011 (Fresno County Annual Crop \& Livestock Report, 2012). 


\section{Research Questions}

- Which parts of Fresno County have the best soil characteristics for the maximum potential pistachios production?

- Are current pistachio lands located in the best locations based on soil characteristics?

- Where is the best location for a new pistachio processing center within Fresno County?

- How much distance, shipping time, fuel cost, and Co2 emission will be saved if a new facility center is built?

\section{Problem Statement}

The current pistachio processing plants and pistachio lands in Fresno County are not optimally located to each other, which cause emissions and costs to increase.

\section{Hypotheses}

An ideally placed processing plant located with respect to pistachio farms in Fresno County can reduce emissions from transportation by $30 \%$ over the current locations.

\section{Objectives}

This study aims to investigate whether pistachios lands and processing facilities are optimally located to each other or not. This study evaluates the current situation and compares it with the case in which one new processing center is built. In addition, this study will find the best location for a new facility center in Fresno County. The other aim of this study is to find and compare the best locations for pistachio cultivation and current pistachio orchards regarding soil quality. The quality of lands is mostly affected by soil characteristics. Also, the study aims to calculate how 
much distance, shipping time, fuel cost, and $\mathrm{Co} 2$ emission will be saved if a new facility center is built.

\section{Justification}

California produces $98 \%$ of pistachios in the U.S (USDA, 2013). According to California Agricultural Statistics Review (2013), pistachio was the sixth largest agricultural export commodity with 2011 exports valued at $\$ 778$ million in California. Consequently, pistachios play an important role in the agricultural export revenue in California. Since this study discusses the best locations for pistachio cultivation according to soil characteristics such as $\mathrm{pH}$, drainage, and texture, it will be beneficial for pistachio growers to know where the most suitable locations for the production are in Fresno County. Moreover, this study provides the growers with information to figure out whether the current pistachio transportation network from farms to facility centers are optimal or not.

This study also will be beneficial to pistachio processors in the Central Valley and can be used as a decision support for them regarding the optimal location for a new processing center in Fresno County. Eventually, results of this study could help in mitigating Co2 emission, fuel cost, and shipping time. 


\section{CHAPTER II}

\section{REVIEW OF THE LITERATURE}

\section{Introduction}

The scope of this study is comparing a current pistachio transportation situation from farms to facilities with consideration of building a new facility and investigating the ideal location of pistachio cultivation in Fresno County. Therefore, a literature review regarding utilizing ArcGIS Network Analysis-location allocation analysis which is applied as the methodology in this study needs to be reviewed. However, it should be considered that this study was unable to locate any articles using ArcGIS Network Analysis-location allocation models in the agricultural sector. As such, in this chapter, an extensive literature review regarding optimizing transportation and finding best locations for different aims utilizing the various location allocation models for decision support is provided.

\section{Optimizing Transportation Using a Location Allocation Model}

Geographic Information Systems (GIS) provide an integrated spatial management environment for the capture, storage, manipulation, management, and mapping of relevant data. GIS provides an interface between the data and map adding the dimension of geographic analysis to information technology. This GIS data analysis makes results easy to present information to key decisionmakers quickly, efficiently, and effectively (Wang, 2010). GIS includes a Network Analyst extension, which can be used for a variety of location allocation problems. There are few studies in the literature which describe methodologies utilizing ArcGIS tools and spatial data with solving location allocation models in agricultural and environmental segments. Also, there are some 
studies that conduct a location analysis in other areas such as public services, emergency service, and supply chain.

Nath, et al. (2000) conducted a study using the ArcGIS and introduced its applications regarding location decisions in an aquaculture study. They believed that ArcGIS is playing an important role in world activities in natural resources management. They used both raster and vector data in ArcGIS to visualize results. Nath, et al. (2000) demonstrated how water resources and land usage type and environmental characteristics with wide range of their categories can be integrated into a map and can show the best locations for aquaculture activities which might be very important for decision makers.

The other application of ArcGIS in agriculture is to obtain the best location for wetland preservation regarding spatial, ecological and cost criteria (Schleupner \& Schneider, 2013). They used a GIS optimization method for a forest and agricultural sector in Europe. They combined this GIS optimization method with a mathematical land use optimization model. Their model finds the areas within a region which fall into different utilization demands and helps evaluate the scarce resources in Europe.

Furthermore, Wang et al. (2004) approached the GIS and location allocation model in their study to obtain the best usage of land in the future for Lake Erhai in China. In their study, they utilized a GIS optimization model considering current land slope and distance. They considered the current land slope and distance to optimize the allocation of the specific number of lands to each different land usage. They provided suggestions regarding the best location and best allocation for the future of this watershed usage based on these factors.

Moreover, Jiangxia et al. (2011) used ArcGIS spatial analysis and linear programming in their study to determine best locations for different kinds of watershed lands. In their study, the 
factors, such as current land use type and slope, were considered. Their outcomes showed that what the best allocation of various watersheds could be in the area. Accordingly, the results help decision makers to manage and develop these watersheds optimally.

Escavy and Herrero, (2013) utilized the ArcGIS location allocation methodology to determine the best locations for gypsum facilities from demand points, which are locations of minerals resources. Their study suggested improvement strategies for the market layout of Spanish gypsum by identifying the optimal facilities locations to cover a significant portion of the market.

Moreover, finding an optimal location for a storage and disposal place for solid wastes in India was conducted by Ghose et al, (2006). ArcGIS location allocation was used to obtain the best disposal place based on the shortest route to transferring wastes to the disposal facility. The factors such as population density, route network, and types of road were considered in their studies shapefiles.

Optimizing the best location for bioenergy facilities in northern Spain was another study which was conducted by Panichelli and Gnansounou (2008). In their study, an ArcGIS location allocation model was used to model competition between facility centers and demand points regarding the least delivery cost (Panichelli \& Gnansounou, 2008).

In addition, Zhang, et al. (2011), introduced an approach to the location problem of biofuel production facilities with a two-stage methodology based on multiple attributes. In the first stage, Geographic Information System is utilized to consider county-based pulpwood distribution, city and village distributions, a federal/state road transportation network, county boundaries, a railroad transportation network, and a population census to identify the feasible locations for the biofuel facility. In the second stage, the optimal location to minimize the total transportation cost is 
identified. This approach is applied in a case study to locate a biofuel production facility in Upper Peninsula of Michigan.

In regards to finding optimal locations, Wood and Brown (2007) utilized another methodology. Their approach used a Center of Gravity model and GIS by providing decision makers with precise and accurate location solutions. The Center of Gravity model is a method that can determine the effectiveness of a location. Moreover, Fuente and Lozano (1998) approached the problems of grouping towns into zones and assigning warehouse to the zones utilizing cluster analysis and Center of Gravity algorithms. They allocated a warehouse to each zone and calculated the location of these warehouses by using a Center of Gravity model. Their study aimed to minimize transportation cost from factories to future warehouses which is part of an optimal operations management.

Chaiken, Ignall, and Walker (1976) conducted multiple studies regarding how to locate a fire station based on a positioning methodology for fire station locations. Their method investigated basic components, methodologies, and concepts of all of the fire station location analysis issues such as travel and response time estimations. While Chaiken et al. (1976) did not develop any kind of mathematical model for the fire station location allocation problem; their study implies the importance of the computer based mathematical formulas for large problems.

Optimizing the location of emergency stations which provide ambulances was another study conducted by Revelle and Snyder (1995). They approached two location allocation analyses for locating optimal emergency stations. One of the methods that they used is the Maximal Covering location problem, which defines the best places for ambulance service. The other method they used is a Facility Location-Equipment Emplacement method allocation, which allocates fire 
services. They used these two different methods because there are different levels of criteria and requirements for service and costs of the ambulance and fire service (Revelle \& Snyder, 1995).

Furthermore, Mitchell et al. (1971) investigated relocating fire stations in a region to serve the population more efficiently utilizing the location allocation model. The location allocation model necessitates the closest fire station to respond to each respective fire incident. Their methodology was based on multiple weights in order to find the best allocations for the fire stations. The weights were defined based on a history of calls related to fire in each part of the region. In this way, the number of fire incidents in each part, the probability of incidents, and potential fire damage were considered. They considered non-weighted variables like a minimum distance traveled by fire engines and incidents of two or more fire engines responding to a call as well.

Optimizing postharvest supply chain was another study discussed by Pitaksringkarn and Taylor (2005). An agricultural facility location model was developed to address the postharvest supply chain. The model aimed to find the shortest path from production centers to markets considering some restrictions such as vehicle routing restrictions. Moreover, their study determined the number, size, and location of markets to balance the product price and transportation cost. This was approached by GIS as an analysis and display tool.

Since transportation services and activities have become efficient, fast, liberalized, and efficient globally, companies have started to unite their distribution activities to a few distribution centers (Morgan, 2007; Oum \& Park, 2003). To have an efficient logistics system playing a critical role in the prosperity and survival of the firm, the number and the location of the united or consolidated distribution centers must be recognized (Manzini \& Accorsi, 2013). Moreover, an 
efficient logistics system in the food supply chain requires producers' location analysis and optimizing the best routes for collecting and distributing the products (Ljungberg et al, 2007).

Moreover regarding optimization of the best routes for collecting and distributing the products, Bosona and Gebresenbet (2011) introduced network integration. They aimed to link supply chain components to collaborate in sharing information to be competitive and have sustainable growth. Their study aimed to investigate the local food supply chain characteristics and develop a framework to coordinate the distribution system resulting in environmental impact reduction, potential market increase, and efficient logistics. They implemented their proposed framework on a case of 19 existing Large-Scale Food Distribution Centers (LSFDC) and 90 local food producers from all over Sweden.

In Bosona and Gebresenbet's (2011) study, GIS and the Center of Gravity method were utilized for location analysis to find the locations of LSFDCs, producers, and determine optimal product collection centers. They employed LogiX and ArcGIS software for route analysis of the food supply chain from farms to collection centers and from collection centers to markets. For food product collection they considered two scenarios: a) producers are in charge of transporting the products, b) collection centers are in charge of handling the products transportation. They conducted a comparison between these two scenarios and demonstrated that the second scenario improved product delivery time, driving distance, and number of routes by $47 \%, 50 \%$, and $68 \%$, respectively. They grouped producers in 14 clusters and about $86 \%$ of these clusters were integrated into LSFDCs, which was able to improve the logistics efficiency, food quality traceability, environmental issues, and potential markets.

There have been various techniques in the literature investigating location analysis problems, including GIS-based location analysis (Li \& Yu, 2005; Hernandez \& Bennison, 2000), 
cluster analysis (Fuente \& Lozano, 1998), Load-Distance technique (Russell \& Taylor, 2009), Center of Gravity technique, and Minimize impedance (P-median) technique (Jamshidi, 2009). These mentioned articles have approached the location allocation analysis to optimize transportation or to find an ideal location of a place by using other methods and tools for different study areas. So far, none of the articles have utilized the location allocation analysis using the minimize impedance method by the ArcGIS Network Analysis tool for an agricultural supply chain problem.

Due to the foregoing, this study investigates a location allocation model in the agricultural supply chain problem by using the ArcGIS Network Analysis tool. As it is described in the beginning of this section, there are few studies utilizing location allocation models for agricultural and environmental problems by different techniques. On the other hand, there are some studies reviewed in this chapter utilizing location allocation models for finding optimal locations for fire stations, emergency services, or warehouses. While most of the studies are using ArcGIS to solve a location allocation model in natural resources or public services problems, this study is using ArcGIS Network Analyst for the food supply chain and more specifically, for pistachios production and transportation location allocation problems. This study aims to evaluate the current transportation situation in Fresno County from pistachio farms to processing centers. Also, finding the ideal location for both a new facility center and pistachio cultivation is another objective of this study. 


\section{CHAPTER III}

\section{METHODOLOGY}

\section{Introduction}

In this chapter, the procedures for data collection and analysis will be explained. Data collection was one of the biggest challenges of this case study, in particular dealing with its availability, consistency and variety of formats. The methods of determining the optimal locations for pistachio orchards will be presented. Procedures for creating the network dataset for further network analysis such as the location allocation and closest facility analysis will be described. Generally, the center of gravity, location allocation, and closest facility analysis are the major analyses that will be discussed in detail in this chapter.

\section{Procedures for Data Collection}

One of the objectives of this study was to evaluate the optimum locations of pistachio orchards based on soil characteristics. As mentioned before, pistachios do best on well-drained, clay/sandy loam soils with $\mathrm{pH} 7$ to 8 . For this study, spatial data, attribute data, and statistical data were used in ESRI ArcGIS for geospatial analysis. For locating optimum locations for pistachio production, spatial data and attributes of different soil characteristics of Fresno County such as soil pH, type,

drain class, surface texture, and area were obtained from the NRCS Web Soil Survey. These spatial data were collected in separate shapefiles. ArcGIS help explains spatial data as "Information about the locations and shapes of geographic features and the relationships between them" (ESRI, 2010). These soil factors were considered for the analysis, and then data was implemented in GIS and the results were compared with current orchards locations. 
Another objective of this study was to compare a current and new situation of pistachio transportation for Fresno County. For this, two scenarios were considered. Scenario 1 considered the current situation of pistachio transportation in Fresno County with existing processing centers. Solving this problem by GIS, the location allocation and closest facility analyses were used. Both analyses evaluated the optimality of pistachio transportation considering shipping distance between pistachio farms and processing centers.

For this study, initial data used for reference in this project included California major roads, interstate streets, and county boundaries, along with background aerial imagery accessed through ESRI's ArcGIS online database resources. The California major roads, interstate streets, and county boundaries were line feature classes and the aerial imagery was raster data. Raster data is defined as image data in the ArcGIS dictionary. Also in the ArcGIS dictionary, feature classes are defined as a set of data that have the same features such as polygons, points, or lines. As simplified, all data should be in the same format. Data should only be presented in polygons format, points format, or only lines format.

Another required data set was current locations of pistachio farms and processing centers. In regards to pistachio orchards, a satellite imagery classified by field crop type was obtained from a USDA National Agricultural Statistics Service (NASS) CropsScape Data Layer. In addition, related data to addresses and locations of existing pistachio processing centers in California were gathered by searching the internet web sources such as American Pistachios Growers, Administrative Committee for Pistachios, and California Pistachio Research Board. As a result, eleven significant facility centers were considered in the Central Valley, including five Paramount facility centers. Two of these facilities are located in Madera County, one in Fresno County, and two in Kern County. Another processing center, Keenan Farms, is located in Kings County. 
Nicholas Farms, ARO Pistachio, Setton Farms, and Monarch Nut are located in Tulare County. Primex Farms is located in Kern County.

Another scenario in this study was scenario 2 which considered the situation of pistachio transportation with a new potential processing center in Fresno County. Regarding the data, current locations of pistachio farms and processing centers were required, and were the same as scenario 1. But, a location of new ideal processing centers should be added to the current processing centers data. For finding the new ideal location of a facility, the Center of Gravity technique was utilized, which is discussed later. After adding coordinates of the ideal location of new facility center to the data, the location allocation and closest facility analyses were used for this scenario as well.

Moreover, this study aimed to calculate the total shipping distance, Co2 emission, transit time, and fuel cost for both scenarios, and then the results were compared. The data obtained from manipulating some parameters such as fuel consumption, fuel efficiency, and an average speed of trucks were from Franzese and Davidson's (2011) study. Also, data regarding producing Co2 emissions and the average cost of diesel fuel were gathered from EIA, (2013).

Consequently, the location allocation and closest facility analyses were analyzed for both scenarios. In addition, total shipping distance, Co2 emission, transit time, and fuel cost were calculated for both scenarios. Then, the comparison displayed the difference between the current and new situation.

\section{Procedures for Data Analysis}

This study was conducted mostly based on pistachio orchards and processing centers data in Fresno County in California. Determining optimum locations for pistachio orchards, a new processing center, and comparing those with the current situation were the major activities carried 
out. Data analysis tools were used including location allocation analysis and closest facility network analysis found in ArcGIS (ESRI, 2010). Some calculations were done using Microsoft Excel.

The key data was location data of pistachio orchards in Fresno County. It was important to obtain the correct feature data for pistachio farms to calculate variables such as $\mathrm{X}$, Y coordinates, acreage, average production, and yield per acre. One source for these kinds of data is the Department of Water Resources, which has most of the crop maps and attributes data for each county in California. However, in this study, the data was not perfectly appropriate, because it just provided the east of Fresno County and the data was not updated beyond 2009. Since pistachio orchards spatial data was captured by satellite imagery and there were many errors of misclassification and incorrect inputs, two parallel comparing procedures were used for defining the correct data.

The first comparison method used for defining the correct pistachio farm locations was comparing the NASS CropScape data with the previously available Department of Water Resources data from 2009. In this study, the most recent raster data of pistachio lands in 2013 from the NASS was used for the location allocation model. The previous updated data for east of Fresno County was in 2009, which was used to compare with 2013 data. This helped to verify the 2013 pistachio lands' data for Eastern Fresno County. Therefore, each 2013 location point was checked individually with 2009 location data by using ArcGIS to consider how many of the locations are shared in both years. In this method, 2009 layer was intersected with the 2013 layer and portions of data that overlap in both layers verified those pistachio orchards locations in 2013.

The second comparing method used for defining the correct data was comparing the 2013 spatial data with the most updated imagery data via Google Maps. For each single location data 
the exact address was searched on Google Maps and zoomed-in to verify whether that land is cultivating pistachios or is just an error in the NASS crop classification. After comparison of more than 200 locations by using these two methods, 105 orchards were verified to be pistachio farms in Fresno County.

Another challenge in working with the geospatial data was the differences in data formats. The NASS CropScape data for pistachio locations was based on satellite imagery, which was based on raster format (image pixels). This format was not useful for the network analysis. In order to be used, pistachio fields' location data needed to be converted into a polygon feature class data type. After converting raster data to polygons with 'Raster to Polygon' command in ArcGIS, there was another problem. Most of the polygons were not exactly matched with dimension of the field on the map. For example, the field was square but the polygon covered half of that area or extended somewhere beside the area. Ideally, they should be placed on the correct field location. For this aim, these converted polygons were further edited in ArcMap via the standard Editing toolbar. For each farm, the exact polygon was drawn meticulously through their perimeters because it was very important for the analysis to have the correct area.

In order to properly represent the orchards in the network analysis, these data should be stored in point format. Therefore, the pistachio orchards should be converted from polygons to points. Consequently, 52 polygons of pistachio orchards were edited in GIS out of the 105 orchards and selected as the cleaned data.

After obtaining the correct farm data, they were implemented in the GIS regarding using the location allocation, and closest facility analyses. Consequently, the results were compared to each other to show which one is the most optimal one. 


\section{Determination of Optimum Locations}

In ArcGIS, one of the most powerful tools is geoprocessing by which it is possible to define, manage, and analyze data and information to make decisions. A typical geoprocessing operation carries out an operation on a dataset such as a feature class, raster, or table and creates a second dataset as the result of that. There are more than 200 available geoprocessing tools in ArcGIS. The most typical commands are Buffer, Dissolve, Intersect, and Clip. Also, geoprocessing provides more complex operations like complicated regression analysis and image classification. The action of cutting features from a layer is defined as Clip, and intersect shows a common features between two layers.

One of the objectives of this study was to evaluate the optimum locations of pistachio orchards based on soil characteristics. In this study, the soil $\mathrm{pH}$ range of 7 to 8 was considered (Demirkiran \& Cengiz, 2013). Therefore, the best soil criteria for having maximum pistachio production were considered as well drained, clay/sandy loam with $\mathrm{pH} 7$ to 8 for our evaluation. The world imagery was obtained from the ESRI ArcGIS Online database. The soil polygons were collected from NRCS Web Soil Survey. Specific attribute data from the NRCS Soils was extracted to ESRI shapefile format using the Soil Data Viewer 6.1 plug-in for ESRI ArcGIS. Initially, the California soil polygons' attribute data had only drain class and soil type information.

The other factor, soil pH, was extracted from NRCS Soils by using the Soil Data Viewer, converted to shapefile, and joined to the existing polygons shapefile. All those factors and soil $\mathrm{pH}$ were combined as an attribute table in a shapefile. Different layers were specified by each soil factor and were shown on the GIS map separately. Then Geoprocessing tools in ArcGIS were used for this analysis. For the analysis, a final result was obtained by selecting data by attributes of soil $\mathrm{pH}$, drain class, and soil type, which were chosen based on the range from 7 to 8 , well drained, 
and Clay Loam/Sandy Loam. Then, the intersect tool that calculates the geometric intersection of any number of layers and feature classes was used. The intersect tool calculated all common inputs between the layers. Therefore, the intersection of these three layers shows the best locations for maximum pistachio production in Fresno County (Figure 5).

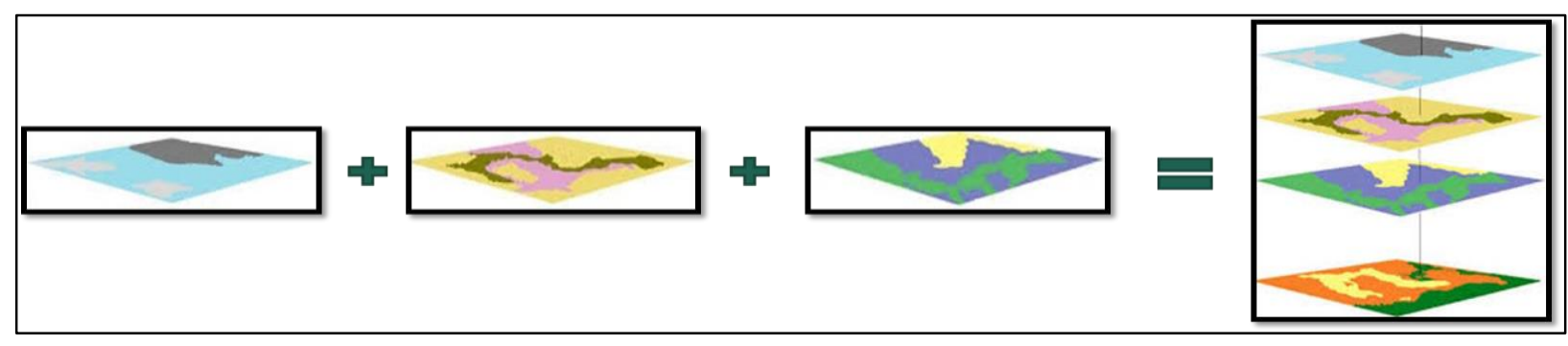

Figure 5. Intersection of three layers.

\section{Center of Gravity Technique}

The Center of Gravity technique was conducted to determine the optimum location of a new processing center. The Center of Gravity Method is a quantitative technique used for finding the location of a facility such as a distribution center or warehouse in a geographic area. The Center of Gravity model is based on weight and distance, rather than strictly locating the geographical center which will minimize distribution distance and cost (Russell \& Taylor, 2009; Ludin \& Nazri, 2008). This model feature is useful for minimizing overall shipping distances. Also, the Center of Gravity model can be used for finding several locations, rather than just one location to minimize shipping distances in a given region.

The coordinates for optimum location could be computed and determined by using the following equations (Russell \& Taylor, 2009): 
1. $X=\frac{\sum_{i} X_{i} Q_{i}}{\sum_{i} Q_{i}}$

2. $Y=\frac{\sum_{i} Y_{i} Q_{i}}{\sum_{i} Q_{i}}$

Where:

$$
\begin{aligned}
& X_{i}=X \text {-coordinate (Longitude) of location } i \\
& Y_{i}=Y \text {-coordinate (Latitude) of location } i \\
& Q_{i}=\text { Quantity of goods moved to or from location } i
\end{aligned}
$$

The major assumption in the Center of Gravity method is that cost is mostly affected by distance and the amount of shipment. The optimal location minimizes the weighted linear distance between the warehouse and its related retailers, where weight is defined as the number of shipped containers (Russell \& Taylor, 2009).

In this study for locating a new processing center in Fresno County, 52 locations were considered for using the Center of Gravity model. Their X and Y coordinates, acreage, average yield per acre, and average production of each farm $\left(\mathrm{Q}_{\mathrm{i}}\right)$ were calculated in the attributes table in ArcGIS.

Consequently, the calculated $\mathrm{X}$ coordinates was used as X-coordinate of location $\mathrm{i}$ and calculated Y coordinates was used as Y-coordinate of location i. The pistachio production of Fresno County for the years of 2013, 2012, and 2011 were equal to 2,188 lb/acre, 2,800 lb/acre, and 3,060 lb/acre respectively, and were gathered from Fresno County annual crop \& livestock report (2013). The average per acre of these three years was 2,682.66 pounds per acre. Then, the product of the production rate and the acreage of each farm were calculated and used as Qi in the 
Center of Gravity model. Consequently, this model calculated the new X and Y coordinates of optimal location of the processing center. For further information regarding the calculation, the Center of Gravity technique calculation table is provided in Appendix B.

\section{Network Analysis}

The ArcGIS Network Analyst extension helps to create a network dataset and conduct analyses on the network dataset. Network-based spatial analysis is suited for problems dealing with transportation networks and service locations. One of the examples of network analysis includes the Closest Facility model. Closest facility analysis measures the nearest facility center based on a specified network cost, which may include measures of route distance, speed limits, or other restrictions, for instance, identifying the nearest fire station for each residence across a community.

Another example of network analysis is the Location Allocation model, which involves finding the best new location for a given service, and other familiar examples such as identifying the shortest transportation route and providing travel directions. Additional dynamic characteristics of network problems such as speed limits, one-way streets, variable speed limits, turn restrictions, and height restrictions can also be included in modeling real network problems (Sandhu \& Chandrasekhar, 2010).

In this study, closest facility and location allocation analysis were used for our research objectives, which evaluated the optimality of pistachio transportation regarding time, and traveling distance between pistachio farms and processing centers. Since Network Analyst is an extension of the basic ArcGIS tool set, the Network Analyst software extension must first be activated with the ArcGIS program. This allows the Network Analyst toolbar to be displayed in addition to the Network Analysis window. In order to begin the analysis, the available roads, orchards, and 
facilities data must first be converted from their original simple points, lines and polygons and reformatted into the specific network dataset (Figure 6), (ESRI, 2010). Network analysis layer properties should be set up based on factors and criteria which are considered by a study. Consequently, performing the analysis and displaying the results would be the last step (Sandhu \& Chandrasekhar, 2010).

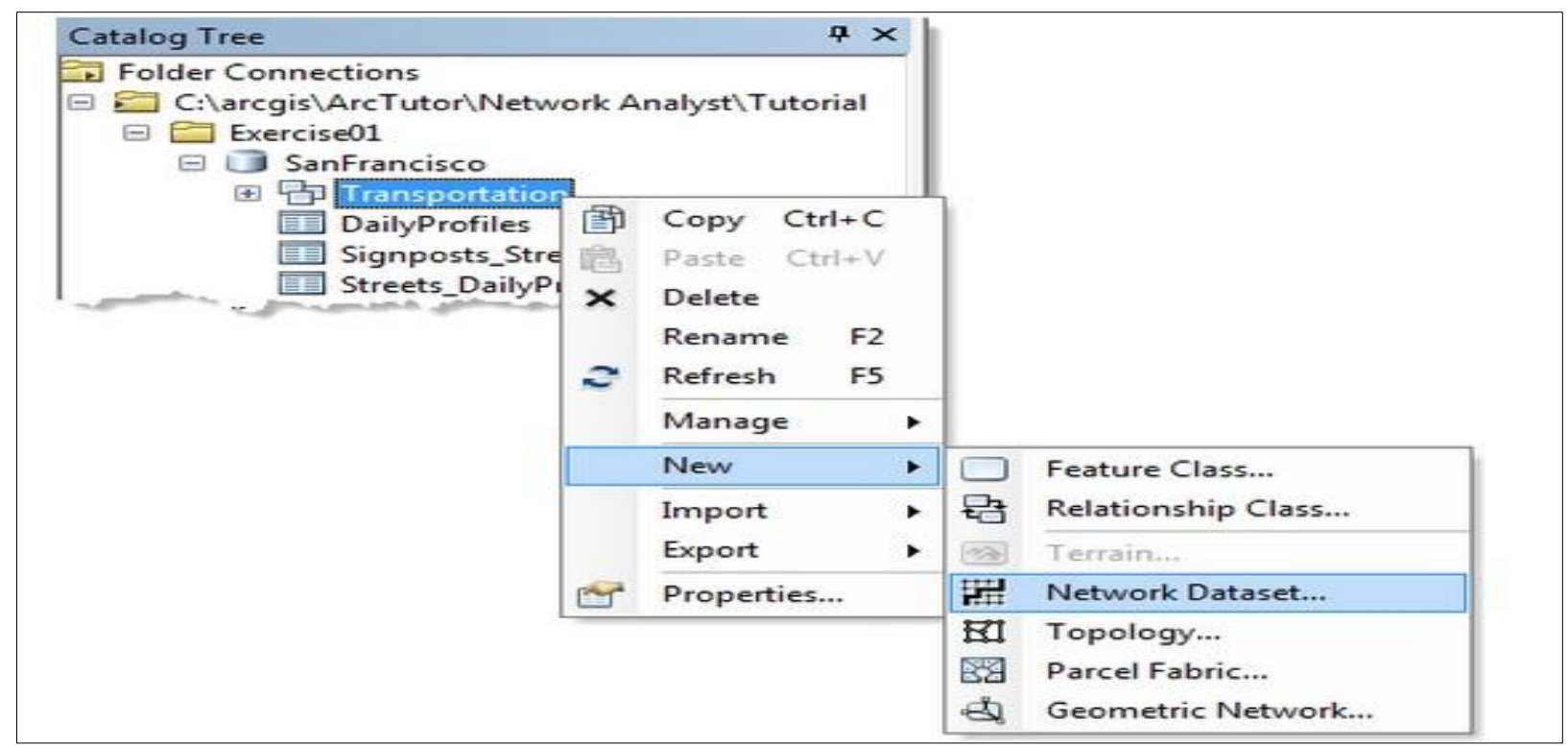

Figure 6. Creating a Network Dataset in ArcGIS.

\section{Network Dataset}

Network datasets are used and created to model transportation networks. They are made from source features, such as lines, points, and turns (ESRI, 2010). The network dataset is built from GIS-based transportation layers such as roads, streets, speed limitation, one-way streets, and turn restrictions to model transportation routes. For creating a network dataset five main steps should be considered. First of all, for creating a geodatabase network dataset, all feature classes including sources in a network should be displayed in one feature dataset. Then, the sources used for creating a network dataset should have fields that show the network impedance values such as distance and travel time (ESRI, 2010). 
For this study, ESRI Roads for Network dataset was used as a major California road feature class, which includes distance. Adding a turn feature class is another step in creating the network dataset. A turn feature class should include fields with information that can be utilized in the network attributes, like turn impedances (for instance, this turn takes two minutes to make) or conditional turning restrictions (for instance, trucks cannot make this turn). But, it is not necessary to use turns for creating a network dataset (Figure 7).

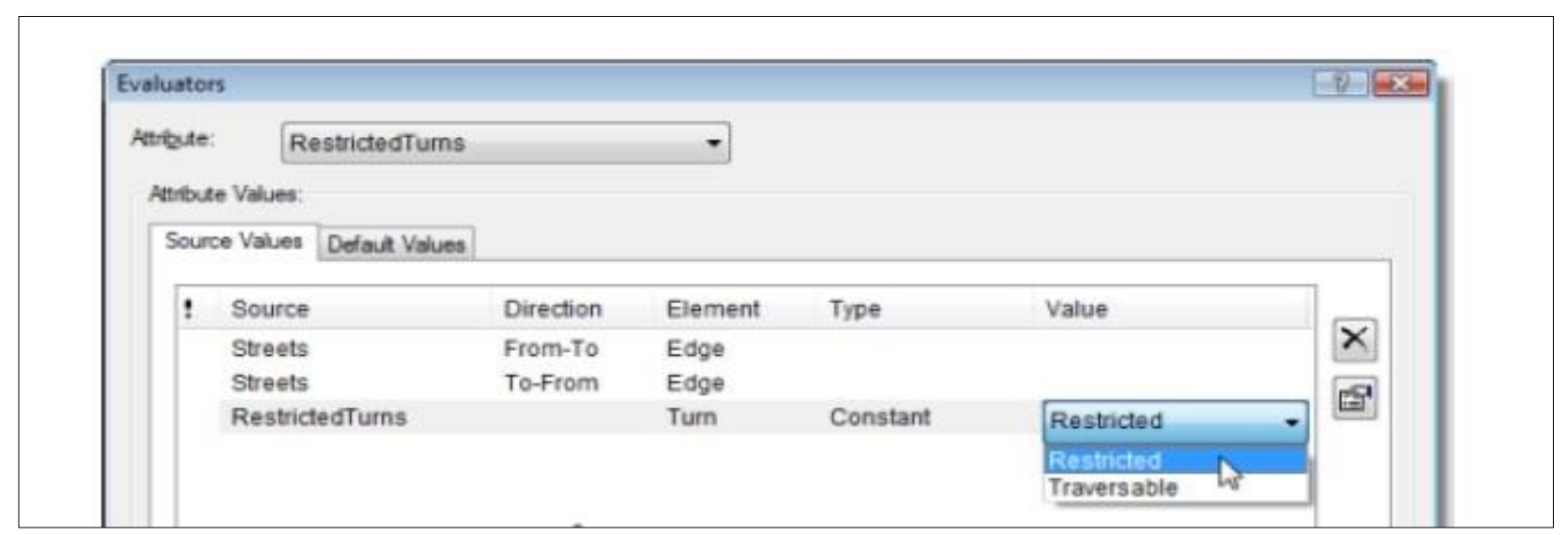

Figure 7. Adding parameters to the Network Dataset in ArcGIS.

After that, the process of creating network components, making connectivity, and assigning values to the defined attributes are done. Accordingly, the network dataset based on the major California road feature class, was used for the network analysis of location allocation and closest facilities identification.

\section{Location Allocation Analysis Model}

The location allocation model is one of the Network Analysis tools in ArcGIS that is an extension to this software. In the location allocation model, there are facilities providing goods and services and demand points consuming these products. The location allocation model aims to find a facility location that supplies the demand points most efficiently. In a location allocation problem, not 
only is the optimal location of a new facility determined, but also the optimal allocation of demand between all of the facilities is addressed (Sandhu \& Chandrasekhar, 2010).

One of the applications of location allocation is to find the best locations for a food processing center in the food supply chain. According to Wakeland et al. (2012), one challenge corresponding to food production is that the location of food facilities can affect emissions. According to Gebresenbet (2011) and Forsman and Paananen (2010), an efficient food logistics improves food packaging products, the vehicle emissions, transport services, transportation time, distance, and routes in the food and agriculture supply chains.

Since the location of facilities plays a critical role in a company's cost structure, one of the strategic decisions in supply chain management is the facility location problem. Therefore, in the supply chain management one of the important factors is location strategy due to its critical role in determining the location of manufacturing based on certain qualities. Since the location of a company greatly affects the fixed and variable costs, companies are trying to benefit from the location decision process.

Depending on the type of product or service, transportation costs can vary (Russell \& Taylor, 2009). Therefore, savings in the transportation of raw material to the company and final products from the company might increase a company's total revenue. Furthermore, wages, taxes, the price of raw materials, and rents are among the expenses influenced by a company's location (Russell \& Taylor, 2009).

The other factor affecting the optimal locations is considering costumer needs. An optimum location for the new facility is defined based on satisfying the requirements of the existing facilities or customers who need the new facility (Chuang, 2002). Oum and Park (2003) 
discussed accessibility of the region, modern logistics services, geographical location, market size, transportation facilities, growth, and potentials of the region as the most important factors for locating distribution centers. Different types of businesses consider the location decision differently. Generally, the objectives of the location decision are minimizing costs, maximizing the benefits, or maximizing profits (Gebresenbet et al, 2011). The location decision is important for a company because the location is both a substantial cost and an income driver (Wood \& Browne, 2007). Therefore, a warehouse location decision considers a combination of cost and speed of delivery (Gebresenbet et al, 2011).

The location allocation model has the ability to solve the problem and find optimal locations efficiently. It is not practical to locate the facilities over obstacles such as a body of water and buildings (Gong et al., 1995). Therefore, setting the properties and uploading a suitable barriers class should be taken into account. Also, in the location allocation problem, it is always presumed that customers choose the closest facility. However, in reality, the closeness of locations may not always be the best choice criteria for customers. Locations can be selected based on priority or types such as specific school, hospital, or market. For example, sometimes customers prefer a specific type of school such as private, public, sports, or art school rather than the nearest one. It is important to consider the consumers' preferences (Lindeskov, 2002).

Location allocation problems can be viewed either as a single criteria decision making problem, such as finding the optimal distance, or a multiple criteria decision making problem such as considering distance and capacity of the facility as decision making criteria. The location allocation problems aim to find the best location or locations for single or multiple facilities optimizing the value of one criterion or multiple criteria (Schietzelt \& Densham, 2003). 
One of the problems which can be solved in the location allocation model is a minimize impedance (P-Median) problem in ArcGIS. This is a technique in the location allocation model which is considered extensively in related studies (Jamshidi, 2009). The P-median problem is the same as minimize impedance in the classical location allocation problem. Minimize impedance is considered as minimizing shipping time or distance in the location allocation problem from demand points to facilities points (Jamshidi, 2009). The P-median problem is utilized to find a private facility such as warehouse or a public facility such as library, airport, and theater in order to minimize the distance or driving time from demand side to facility side. By minimizing the distance, the final objective is to minimize the transportation cost (Jamshidi, 2009). Distance in the classical P median location allocation problem is assumed as a straight line from a facility center to a demand point (Min et al., 1998). However, in some software programs, such as ArcGIS and Flowmap, routing analysis is assumed to be closely related to the location allocation problem and is considered as one of the criteria in the problem. The routes play an important role for the location allocation problems such as dedicating an ambulance where an emergency patient needs to be reached in minimum time (Sasaki et al., 2010).

Minimize impedance is utilized to approach locating warehouses through minimizing transportation costs of delivering goods to outlets. Minimize Impedance reduces the overall travelling distance required to reach the facilities. In other words, to find optimum locations of facilities, the sum of the (weighted) distance between each demand location and the nearest facility will be minimized. Since this study aims to allocate the farms to the processing centers optimally and minimize overall traveling distance from farms to the processing centers, it uses "Minimize Impedance" for the analyses. Therefore, the best-fitted model is minimizing impedance which reduces the total transportation costs of delivering products. 
The location allocation analysis layer can be created from the Network Analyst toolbar by clicking Network Analyst > new location allocation. Then it is popped up on the Network Analyst window with six network analysis classes at the left side of ArcMap window. Classes include Facilities, Demand Points, Lines, Point Barriers, Line Barriers, and Polygon Barriers.

One of the classes is a facility class which means a point feature class indicating a facility, warehouse, or processing center. Each facility can have a weight that shows the importance or attractiveness of that. In this study, locating the processing centers is done by considering a weight value of one because weight value more than one can only be employed for the maximize target market share problems. For example, the larger demand point would have a weight of 2.0 and the normally sized one would have a weight of 1.0 , so careful consideration is required for determining what factors impact facility weight.

Demands Point class is usually a location indicating the demand for the goods and services that facilities provide. The demand point can be a ZIP Code, which is weighted by the number of consumers living within it or by the expected consumption; also these points can indicate business customers. In this study, eleven facility centers were identified in the Central Valley. These facilities include five Paramount facility centers, Keenan Farms, Nicholas Farms, ARO Pistachio, Setton Farms, Monarch Nut, and Primex Farms. Addresses for each location were Geocoded in ArcGIS and used as a Facilities class in the location allocation model. In addition, all 52 pistachio farms were converted from polygons to points for using as a demand points class in this model. This analysis was solved twice for both existing situation and with new processing center for comparing the results.

The routes class of Network Analyst provides the results or output for route-based features calculated by the solver during the analysis process. For example, the route class contains the line 
features (route) that link demand points to the facility centers to which they are allocated (Sandhu \& Chandrasekhar, 2010). Point, Line, and Polygon Barriers are different types of feature classes that sometimes in an analysis define the barriers such as a river, railroad or building. In this study, an incorrect result occurred because there was a wrong connection in the border of Fresno and Madera County, which was close to one of the pistachio orchards. A line barrier was created for solving this problem. The line barrier was created along part of this border with editing tools and added to the line barriers class.

These classes have attributes indicating the inputs and outputs for a given location allocation problems. The location allocation layer keeps the network analysis objects such as inputs and parameters. Network analysis objects are features and records used as input and output during network analysis such as barriers, routes, and facilities. Once the analysis layer is created, the objects should be added, and parameters for the analysis objects should be set up. In this study, spatial locations of pistachio orchards and processing centers are considered as demand and facility classes, respectively. It is only possible to add objects to input classes not to any results classes made by the solver. Next, properties of the network analysis layer should be set up based on different criteria for each problem (Table 1). Then the network problem is solved by the analysis and given the results for the location allocation problem (ESRI, 2010). Therefore, after having input into our model and setting criteria of the model, the result is displayed as a map. The location allocation analysis settings and criteria are set up for two scenarios based on Table 1 . 
Table 1. Location Allocation Analysis Settings for Two Scenarios

\begin{tabular}{|c|c|}
\hline Location Allocation-Scenario 1 & Location Allocation- Scenario 2 \\
\hline $\begin{array}{l}\text { - } \text { Problem Type: Minimize Impedance } \\
\text { - Facilities to Choose: } 11 \\
\text { - Impedance Cutoff: None } \\
\text { - Impedance Transformation: Linear } \\
\text { - Impedance: Distance (meters) } \\
\text { - Travel From: Demand to Facility } \\
\text { - U-Turns at Junctions: Allowed }\end{array}$ & $\begin{array}{l}\text { - } \text { Problem Type: Minimize Impedance } \\
\text { - Facilities to Choose: } 12 \\
\text { - Impedance Cutoff: None } \\
\text { - Impedance Transformation: Linear } \\
\text { - Impedance: Distance (meters) } \\
\text { - Travel From: Demand to Facility } \\
\text { - } \quad \text { U-Turns at Junctions: Allowed }\end{array}$ \\
\hline
\end{tabular}

\section{Closest Facility Model}

A closest facility analysis layer measures the nearest facility center and incidents based on a specified network cost. There could be options to set how many facilities to find and specify in which direction to detect toward or away from them. The closest facility analysis layer determines the best direction from a demand point to a facility center based on travel costs. The closest facility layer has six classes including Facilities class, Incidents class, Routes class, Point, line, and polygon barriers classes. A facility class is a point feature class that indicates a candidate facility or processing center. Incident class keeps the network locations, which are used as starting or ending points in closest facility analysis. In this model, again all 52 pistachio farms were converted from polygons to points for using as an incident class in this model.

In addition, eleven geocoded existing centers' addresses were used as a Facilities class in this model. This analysis was solved twice for both scenario 1 and scenario 2 as well. Routes class reports the resulting routes between facilities and incidents. Same as the location allocation layer, this class is the output-only class, which means it is made by the solver. A line barrier is considered for the closest facility analysis because there is a wrong route connection in the border of Fresno and Madera County that provides an incorrect result. A line barrier is created along part of Fresno and Madera County with editing tools and added to the line barriers class. 
When the closest facility analysis layer is produced, the classes are empty. The point, line, and polygon barriers are optional, but a minimum of one incident and one facility is required to solve the problem and must be added. The closest facility analysis settings and criteria are set up for two scenarios based on Table 2 .

Table 2. Closest Facility Analysis Settings for Two Scenarios

\begin{tabular}{|l|ll|}
\hline Closest Facility-Scenario 1 & \multicolumn{1}{|c|}{ Closest Facility-Scenario 2 } \\
\hline - Impedance: Distance (meters) & - Impedance: Distance (meters) \\
- Default Cutoff Value: None & - Default Cutoff Value: None \\
- Destinations to Find: All & - Destinations to Find: All \\
- Facility to Find: 11 & - Facility to Find: 12 \\
- Travel From: Incident to Facility & - Travel From: Incident to Facility \\
- U-Turns Allowed at Junction: Allowed & - U-Turns Allowed at Junction: Allowed \\
\hline
\end{tabular}

\section{Calculation of Distance, Fuel Cost, Co2 Emissions, and Time}

In Table 3, the average weight, fuel consumption, efficiency, and average speed of a truck, which are needed for further assessments, are obtained from the study of Franzese and Davidson, (2011). In their study, fuel consumption and efficiency were calculated based on a speed of 64.9 (mph), however, the highway and rural speed limit for trucks is 55 (mph) in California. Since a truck is not driving on highways all of the time, we assume that the average speed is less than 55 and is equal to 52.5 .

Consequently, other variables such as fuel consumption and fuel efficiencies are changed based on this speed. The parameters such as the average weight and distance traveled were considered fixed factors. Therefore, the average truck weight is considered 55,468 pounds according to Franzese and Davidson's (2011) study. The fuel consumption and fuel efficiency (Miles per Gallon) were calculated based on $52.5 \mathrm{mph}$ by using cross-multiplication. The fuel 
consumption and speed has a direct relation; however, the fuel efficiency (Miles per Gallon) and speed has the inverse relation. Also, the product of average weight (ton) by miles per gallon is equal to fuel efficiency (ton-miles per gallon). Consequently, new parameters which are considered for further assessments are shown in Table 4.

Table 3. Original Average Weight and Fuel Consumption of a Truck

\begin{tabular}{|c|c|c|c|c|c|c|}
\hline $\begin{array}{c}\text { Truck Weight } \\
\text { Capacity Range } \\
\text { (Pounds) }\end{array}$ & $\begin{array}{c}\text { Average } \\
\text { Weight } \\
\text { (Pounds) }\end{array}$ & $\begin{array}{c}\text { Distance } \\
\text { Traveled } \\
\text { (Miles) }\end{array}$ & $\begin{array}{c}\text { Fuel } \\
\text { Consumed } \\
\text { (Gallons) }\end{array}$ & $\begin{array}{c}\text { Fuel Efficiency } \\
\text { (Miles per } \\
\text { Gallon) }\end{array}$ & $\begin{array}{c}\text { Fuel Efficiency } \\
\text { (Ton-miles per } \\
\text { Gallon) }\end{array}$ & $\begin{array}{c}\text { Average } \\
\text { Speed } \\
(\mathrm{mph})\end{array}$ \\
\hline $50,000-60,000$ & 55,468 & 541.2 & 63.3 & 8.6 & 237 & 64.9 \\
\hline
\end{tabular}

Note: The product of average weight by miles per gallon is equal to Ton-miles per gallon.

Source: Franzese, O., \& Davidson, D. (2011). Effect of weight and roadway grade on the fuel economy of class-8 freight trucks. Oak Ridge National Laboratory, Tennessee, USA.

Table 4. Average Weight and Fuel Consumption of a Truck

\begin{tabular}{|c|c|c|c|c|c|c|}
\hline $\begin{array}{c}\text { Truck Weight } \\
\text { Capacity Range } \\
\text { (Pounds) }\end{array}$ & $\begin{array}{c}\text { Average } \\
\text { Weight } \\
\text { (Pounds) }\end{array}$ & $\begin{array}{c}\text { Distance } \\
\text { Traveled } \\
\text { (Miles) }\end{array}$ & $\begin{array}{c}\text { Fuel } \\
\text { Consumed } \\
\text { (Gallons) }\end{array}$ & $\begin{array}{c}\text { Fuel Efficiency } \\
\text { (Miles per } \\
\text { Gallon) }\end{array}$ & $\begin{array}{c}\text { Fuel Efficiency } \\
\text { (Ton-miles per } \\
\text { Gallon) }\end{array}$ & $\begin{array}{c}\text { Average } \\
\text { Speed } \\
\text { (mph) }\end{array}$ \\
\hline $50,000-60,000$ & 55,468 & 541.2 & 51.2 & 10.63 & 293 & 52.5 \\
\hline
\end{tabular}

For computing total distance for trucks per farms in scenarios 1 and 2, the total production (pounds per farm) was divided by the average truck weight capacity. Then, the result is the number of required trucks per farm. The multiplication of the number of trucks for each farm and the distance the truck needs to drive from each farm to a processing center, equals the total distance for each farm driven by its trucks (Example 1). 
Example 1:

Total distance for all trucks per farm $1=\mathrm{TDF}_{1}=$ Total \# of needed trucks for farm $1 \times$ their distance driven.

It is assumed that every truck ships one load of product from a farm to a processing center with a full load of products, so the route that an empty truck drives back from a processing center to a farm is not considered for this calculation. Due to all of the calculations being based on full trucks and the fact that they are empty on reverse directions to farms. Therefore, reverse distances are not considered in this study. Thus, the summation of all the distances for each farm is the total distance driven in each scenario. In scenario 2, the new center is added for the assessment; including, all of the calculation being conducted with considering the location of new center in the area.

3. Total of distance in scenario $1=\sum_{i} T D F_{i}$

The total number of gallons of diesel per scenario is calculated based on fuel efficiency (293 ton-miles per gallon) and the total mileage for each scenario. For further calculation, the total distance is converted to miles and the average weight is converted to tons from pounds, which is 27.73 tons $(55,468 \mathrm{lb}=27.73$ tons $)$, (Franzese \& Davidson, 2011). Then, for each scenario, tonmiles was calculated by taking the product of total distance in miles by 27.73 tons equals. By cross multiplication, the number of gallons which is consumed for total distance under each scenario is assessed.

4. Mile*Ton=Total distance (mile) $\times 27.73$ (Ton)

5. Total \# Gallons $=\frac{\text { Mile*Ton }}{293}$ 
When the total number of gallons for each scenario is calculated, it is divided by the total number of trucks for each scenario and it reflects the average number of gallons per truck in a harvesting season.

6. Average \# gallons per truck $=\frac{\text { Total gallons }}{\text { Total \#truck }}$

Next, for scenarios 1 and 2, the average number of gallons per truck is assessed. Subtracting these two numbers show how many gallons of diesel fuel per truck can be saved by using a new facility in the harvesting season averagely.

According to EIA (2014), about 22.38 pounds of $\mathrm{Co} 2$ are produced by burning a gallon of diesel fuel. Therefore, the product of the total number of gallons times 22.38 pounds would be the total of $\mathrm{Co} 2$ in pounds produced for each scenario.

7. Total Co2 $=$ Total \# Gallons $\times 22.38 \mathrm{lb}$

For the fuel cost, the calculation is the product of the total required diesel gallons times $\$ 4.11$ (California average diesel price per gallon from Sep $15^{\text {th }}, 2013$ to Dec $10^{\text {th }}, 2013$ ) which is the harvest period (EIA, 2013).

\section{Fuel Cost $(\$)=$ Total \# Gallons $\times \$ 4.11 /$ Gallon}

Regarding the calculation of shipping time, based on Table 4, is the total distance of each scenario divided by the average speed of $52.5 \mathrm{mph}$. Then, the results are compared for the two scenarios in the results chapter.

$$
\text { 9. } \operatorname{Time}(\mathrm{h})=\frac{\text { Total distance }(\mathrm{mile})}{\text { Average speed }(\mathrm{mph})}
$$


The above calculations are based on the average speed of $52.5 \mathrm{mph}$ which is the assumption of this study to show the mathematical procedure, however, a sensitivity analysis is done on the average speed changing from $30 \mathrm{mph}$ to $60 \mathrm{mph}$ in $5 \mathrm{mph}$ unit intervals. The sensitivity analysis table shows that different average speed ranges do not change the saving percentage, although, the amount of each variable is changed (Table 5). Since, the total distance in both scenarios are the same for the different average speed, and there is a linear relationship between variables; the saving parentage is not going to change for all of the considered variables in this study.

Table 5. Comparing Distance, Co2, Fuel Cost, and Travel Time in Scenarios 1 and 2 over a Harvesting Season for Various Speed Values - Sensitivity Analysis

\begin{tabular}{|c|c|c|c|c|c|c|c|c|}
\hline $\begin{array}{c}\text { Speed } \\
(\mathbf{m p h})\end{array}$ & $\begin{array}{c}\text { Distance } \\
\text { Scenario 1 } \\
\text { (miles) }\end{array}$ & $\begin{array}{c}\text { Distance } \\
\text { Scenario 2 } \\
(\mathbf{m i l e s )}\end{array}$ & $\begin{array}{c}\text { Scenario 1 } \\
\mathbf{( l b )}\end{array}$ & $\begin{array}{c}\text { Co2 } \\
\text { Scenario 2 } \\
\mathbf{( l b )}\end{array}$ & $\begin{array}{c}\text { Fuel Cost } \\
\text { Scenario 1 } \\
\mathbf{( \$ )}\end{array}$ & $\begin{array}{c}\text { Fuel Cost } \\
\text { Scenario 2 } \\
\mathbf{( \$ )}\end{array}$ & $\begin{array}{c}\text { Time } \\
\text { Scenario 1 } \\
\mathbf{( h )}\end{array}$ & $\begin{array}{c}\text { Time } \\
\text { Scenario 2 } \\
(\mathbf{h})\end{array}$ \\
\hline 30 & $33,662.93$ & $19,956.03$ & $40,493.95$ & $24,005.59$ & $7,436.56$ & $4,408.53$ & $1,122.10$ & 665.20 \\
\hline 35 & $33,662.93$ & $19,956.03$ & $47,242.94$ & $28,006.52$ & $8,675.98$ & $5,143.29$ & 961.80 & 570.17 \\
\hline 40 & $33,662.93$ & $19,956.03$ & $53,991.93$ & $32,007.45$ & $9,915.41$ & $5,878.04$ & 841.57 & 498.90 \\
\hline 45 & $33,662.93$ & $19,956.03$ & $60,740.92$ & $36,008.38$ & $11,154.83$ & $6,612.80$ & 748.07 & 443.47 \\
\hline 50 & $33,662.93$ & $19,956.03$ & $67,489.91$ & $40,009.31$ & $12,394.26$ & $7,347.55$ & 673.26 & 399.12 \\
\hline 55 & $33,662.93$ & $19,956.03$ & $74,238.90$ & $44,010.24$ & $13,633.69$ & $8,082.31$ & 612.05 & 362.84 \\
\hline 60 & $33,662.93$ & $19,956.03$ & $80,987.89$ & $48,011.17$ & $14,873.11$ & $8,817.07$ & 561.05 & 332.60 \\
\hline
\end{tabular}

\section{Major Assumptions for Orchards and Processing Centers}

Some major assumptions for orchards were considered for this study. One of them is consideration of the same ownership for all the orchards next to each-other. The adjacency of several fields for a farm and their similar addresses led to some situations which might confuse the analysis and create the wrong results in ArcGIS software. Consequently, for convenient computations and avoiding errors, the pistachio orchards which are next to each other and have common borders are assumed to belong to one person and were merged. This assumption might not match the reality; 
however, it does not affect the overall computation process. Relaxing this assumption introduces new farms and results in more computations.

Another assumption is in the location allocation and closest facility analyses, where each farm chooses the closest facility to ship its production to. However, this assumption might not match the reality; for example, each farm has a contract to ship its production to a specific facility, no matter how much further it is located. On the other hand, it is possible that a processing center makes decisions to choose farms to buy and ship the production from farms to the facility, because of different factors such as quality and price of pistachios, or different contracts, no matter how great the distance of the farm. Consequently, it was assumed current pistachio orchards make decisions to ship their production and select a closest facility in the area.

Regarding ideal locations for the pistachio cultivation, this study has not investigated what currently is in the ideal soil locations. It is possible that other current crops which have the same requirements for maximum yields are in these locations. This study assumed just to find the optimal location and did not consider any constraints for feasible locations other than pistachios.

Moreover, regarding processing centers in the Central Valley, there was not any available data, except locations, the name of companies, and some general irrelevant information. Therefore, it is assumed that there were not any limits placed on demands by facilities in this study.

\section{Major Assumptions for Trucks}

Other assumptions are regarding the speed of trucks, weight, and direction ways. Speed limit for both the highways and rural routes for trucks is $55(\mathrm{mph})$ in California. Since trucks are not driving on highways all of the time, and the average speed of them depend on different factors, which are beyond the scope of this study; it is assumed that the average speed is less than $55 \mathrm{mph}$ and equal 
to $52.5 \mathrm{mph}$. Consequently, other variables such as fuel consumption and fuel efficiencies are changed based on this speed.

Another assumption is the average weight of truck capacity which is assumed 55,468 pounds based on Franzese and Davidson's (2011) article. Regarding the direction way assumption, only the shipping distance from a farm to a processing center is considered in this study. Because in this direction, it is assumed a truck has a full load of products with average truck weight of 55,468 pounds. Therefore, the route that a truck drives back from a processing center to the farms is not considered for this study. 


\section{CHAPTER IV}

\section{RESULTS}

\section{Introduction}

In this chapter the results of implementing of the location allocation model for two scenarios will be compared with each other. One of the scenarios considers the current situation of pistachios transportation in Fresno County and the other one assumes the situation with the new potential facility center. However, first the optimum location of pistachio cultivation will be analyzed, and the location of a new facility center will be found. A comparison between the best places and the current orchards will also be conducted. At the end of this chapter, the comparison between the results of two scenarios in the location allocation model displays the difference between objective variables such as distance, Co2 emissions, fuel cost, and travel time.

\section{Fresno County}

Figure 8 shows Fresno County with a black border between other counties in the Central Valley in California. Madera County is above Fresno County and three counties of Kings, Tulare, and Kern are located below Fresno County. These counties are shown because of locations of processing centers in the Central Valley. In addition, Fresno County pistachio farms and current processing centers are shown with blue color and green triangle symbols in Figure 8, respectively. There are 52 selected orchards, which are the results of merging all adjacent orchards together. Total acreage was estimated $39,896.67$ acres with the production of $107,029,252$ pounds by ArcGIS software. The map also shows that only one processing center, Paramount Plant, is specifically in Fresno County. 


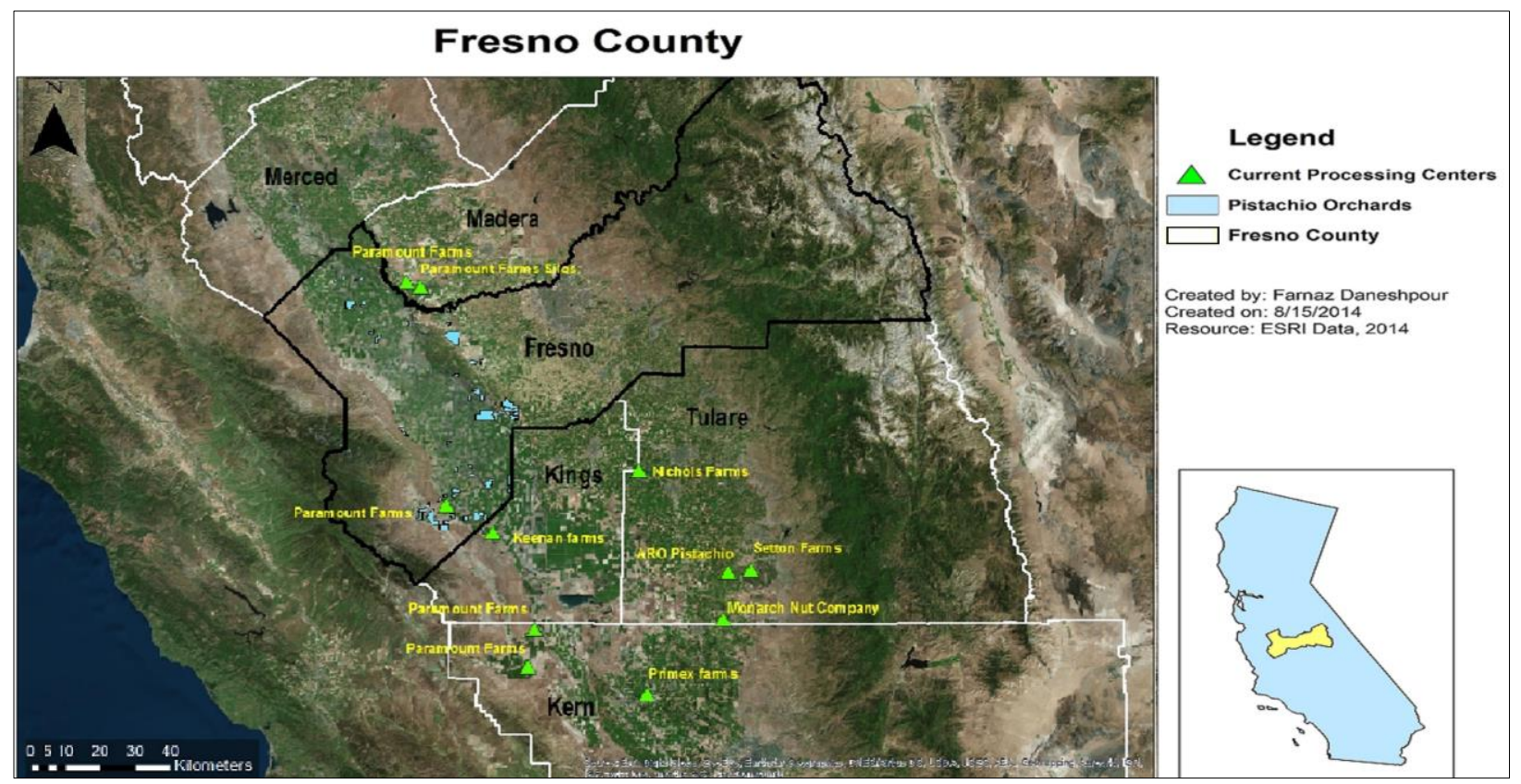

Figure 8. California Central Valley and Fresno County. Source: Esri Data, 2014.

\section{Determination of Optimum Locations}

One of the objectives of this study was to determine the optimum locations of pistachio orchards based on soil characteristics such as $\mathrm{pH}$ from 7 to 8 range, well drained, and clay loam/sandy loam type due to their importance for the optimal pistachio production.

In Figure 9, the ideal locations are shown in the map with light green color. These locations were selected based on all three assumed criteria (soil $\mathrm{pH}$, soil type, and drain class). The result of intersecting all these three characteristics in the map shows the best potential locations which are located on the west side of Fresno County. Also, the area with soil surface texture filled with purple color is defined as clay loam and the pink ones represent sandy loam. 


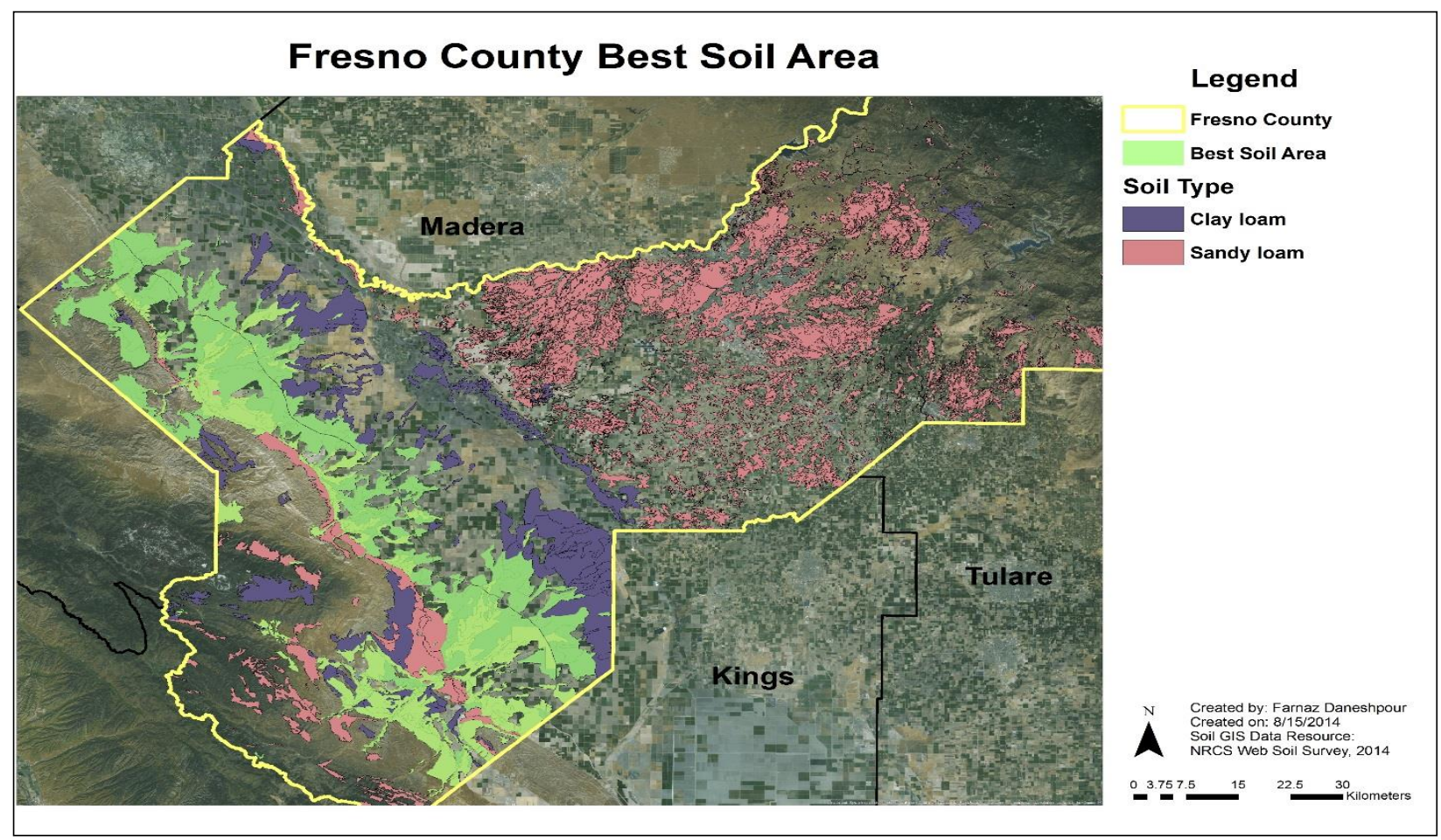

Figure 9. Fresno County Best Soil Area. Source: NRCS Web Soil Survey, 2014.

Figure 10 shows Fresno County best soil area with pink color and current pistachio orchards all around Fresno County with yellow color, and identifies the current pistachio orchards comparing with potential locations. Comparing these locations with each other, shows current farms are not optimally located in Fresno County for optimal production. There are only few orchards placed on the best soil. 


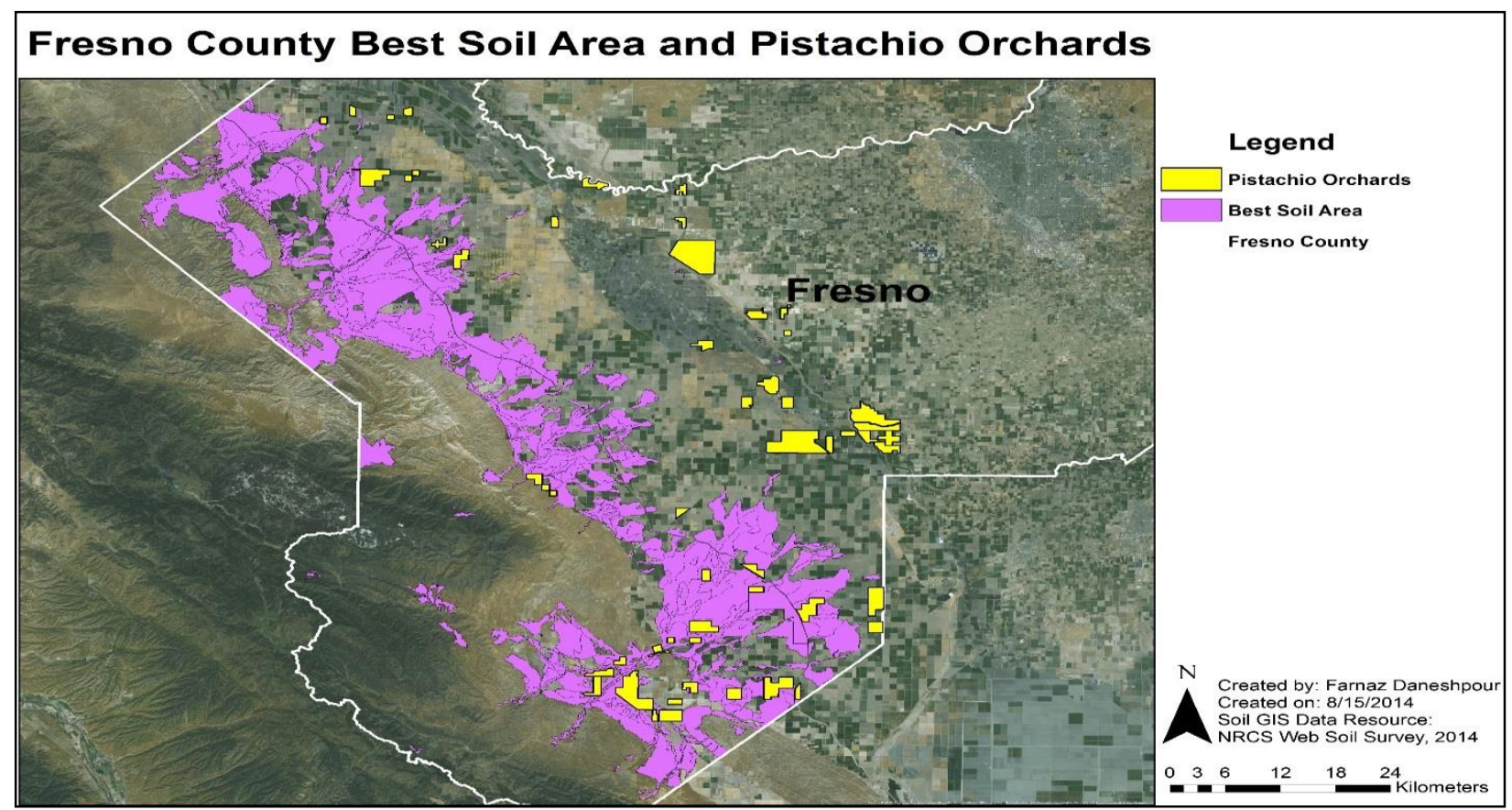

Figure 10. Comparing Pistachio Orchards Acreage and Production with Best Area. Source: NRCS Web Soil Survey, 2014.

In Table 6, acreage was estimated at 39,896.67 acres with the production of 107,029,252 pounds by ArcGIS software. Also, it is shown that there is only 10,645 acres of pistachio farms from the total of 39,897 acres $(26.7 \%)$ located in the optimal area. From another perspective, there is only $3.22 \%$ of the best soil locations covered by pistachio cultivation. It is assumed that the pistachio production could increase significantly if farmers consider these identified areas for the future cultivation due to their importance for the maximum productivity. Also, there might be other crops that can be produced very well in this selected locations based on soil characteristics, and they might be more profitable crops than pistachios.

Table 6. Comparing Pistachio Orchards' Acreage and Production with Best Area

\begin{tabular}{|l|c|c|c|}
\hline & Ideal Pistachio Farms & Total Pistachio Farms & Best Area \\
\hline Acreage & 10,645 & 39,897 & 330,546 \\
\hline Production (lb) & $28,557,794$ & $107,029,252$ & - \\
\hline
\end{tabular}




\section{Center of Gravity Model}

The Center of Gravity Method as a quantitative technique was used for identifying the location of the new facility center in a geographic area of Fresno County based on demand points' weight and distance that minimized distribution distance and costs. The coordinates of the new facility center were added to the facility classes for the location allocation and closest facility analyses in scenario 2. The study of a potential location using the gravity model has given a result in allocating pistachio farms. In this study, using the gravity model with the application of GIS, spatial data and attribute data were considered and analyzed, and the optimal center has been shown graphically.

In Figure 11, the location of new processing center is shown in the Central Valley with a yellow star symbol, compared with locations of other pistachio processing centers. The new processing center is located in the west side of Fresno County with X-coordinate of 1900000 and Y- coordinate of 620772.

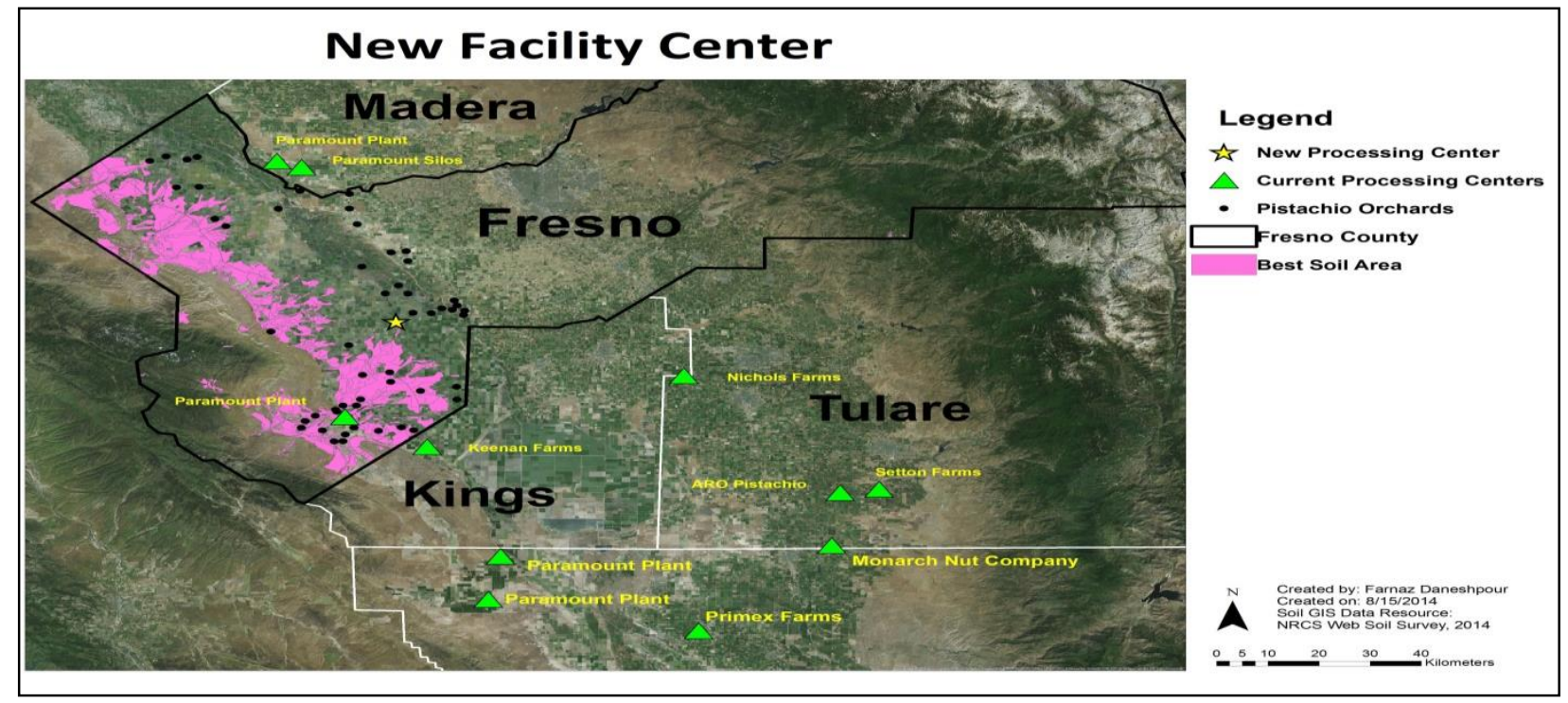

Figure 11. New Facility Center with Counties View. 


\section{Location Allocation}

Scenario 1 assumed to allocate demands to the nearest facility centers considering current situation. And, scenario 2 investigated the allocation of demands to the nearest facility considering a new potential facility in Fresno County. Regarding using data as input in the location allocation model, information for facility centers and demand points are necessary. Data from pistachio orchards in Fresno County were considered as demand points for applying into the location allocation model. Both demands and facilities information were used in the location analysis in shapefiles format. Shape format is a widely used format for ArcGIS Software. Therefore, shape format was used in the analysis as the data input format.

Allocating farms to the facilities in Fresno County based on minimize impedance in the location allocation problem was the goal. The analysis was conducted based on distance, which was considered in the model through the road network data. The results were analyzed and compared with each other based on the road network dataset.

In Figure 12, allocation of pistachio orchards to the corresponding current and the new processing facility is shown with blue straight lines. These straight lines demonstrate the connection lines from the demand points to the facility center and depict which demand points are allocated to which facility centers. Also, the ideal location of new processing center is shown with a yellow star symbol and current processing centers and farms are shown with green triangles and black dots symbols respectively. In scenario 1 , there are only three facilities that were selected by the solver (two Paramount plants, one in Madera County and the other in Fresno County, and Keenan Farms in Kings County). On the other hand, five farms could not be allocated due to long distance in the optimal situation. 
In scenario 2, the spatial distribution of locations and demands with the new optimal facility center show that the new facility center captures the most demand points in the area. As a result, all the farms were selected for an optimal allocation. It is shown that the new facility center captures 20 pistachios farms, which is quite a large number compared with other processing centers.

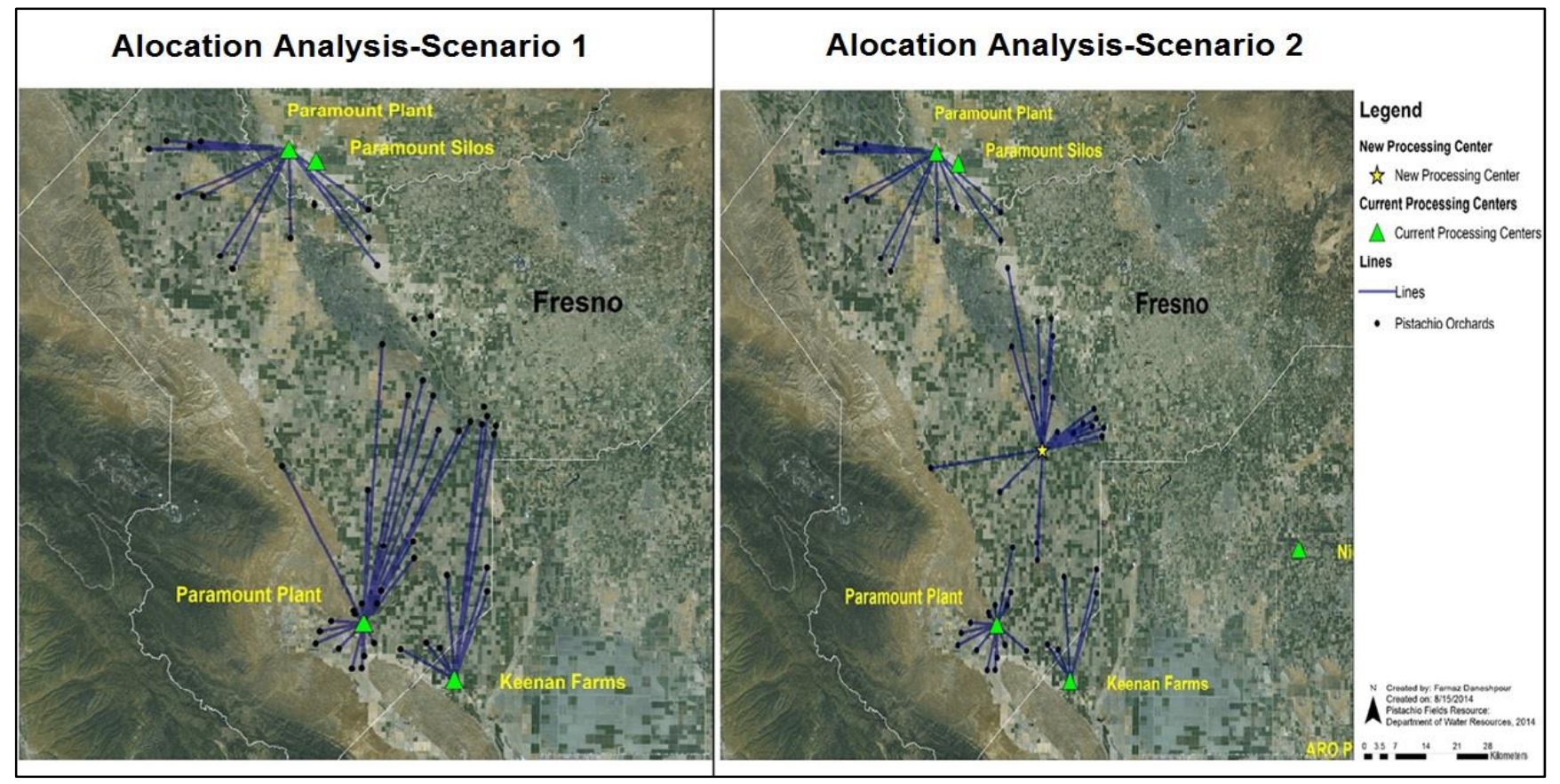

Figure 12. Comparing Location Allocation Scenario 1 and 2.

\section{Closest Facility}

In the Closest Facility model, like the location allocation model, two scenarios were considered. In the first scenario, the goal was to find the nearest facility centers to demand points considering shortest distance. In the second scenario, finding the nearest facility centers to demand points was analyzed by considering the new potential facility in Fresno County. For applying the closest facility analysis, pistachio orchards' location data in Fresno County were considered as incidents 
(demand points). In addition, facilities locations information was used as the facility class layer. Then, the results were analyzed and compared with each other based on the road network dataset.

In Figure 13, allocated pistachio orchards to the corresponding current and new processing facility are shown with blue lines. Each farm is connected to the closest facility by blue lines that show the driving directions on the map. In Figure 13, the optimal location of a new processing center is shown with a yellow star symbol, and current processing centers and farms are shown with green triangles and red dots symbol respectively.

As a result, there are only four facilities (three Paramount plants two of which are located in Madera County and one in Fresno County, and one plant at Keenan Farms in Kings County) that were selected by the solver among the 11 facilities in scenario 1 . In scenario 2 , there are four facilities that were selected by the solver among all 12 facilities (two Paramount plants, one in Madera County and one in Fresno County, Keenan Farms in Kings County, and the new processing center in Fresno County). On the other hand, all of the farms could be allocated to the closest facility in the optimal way. 


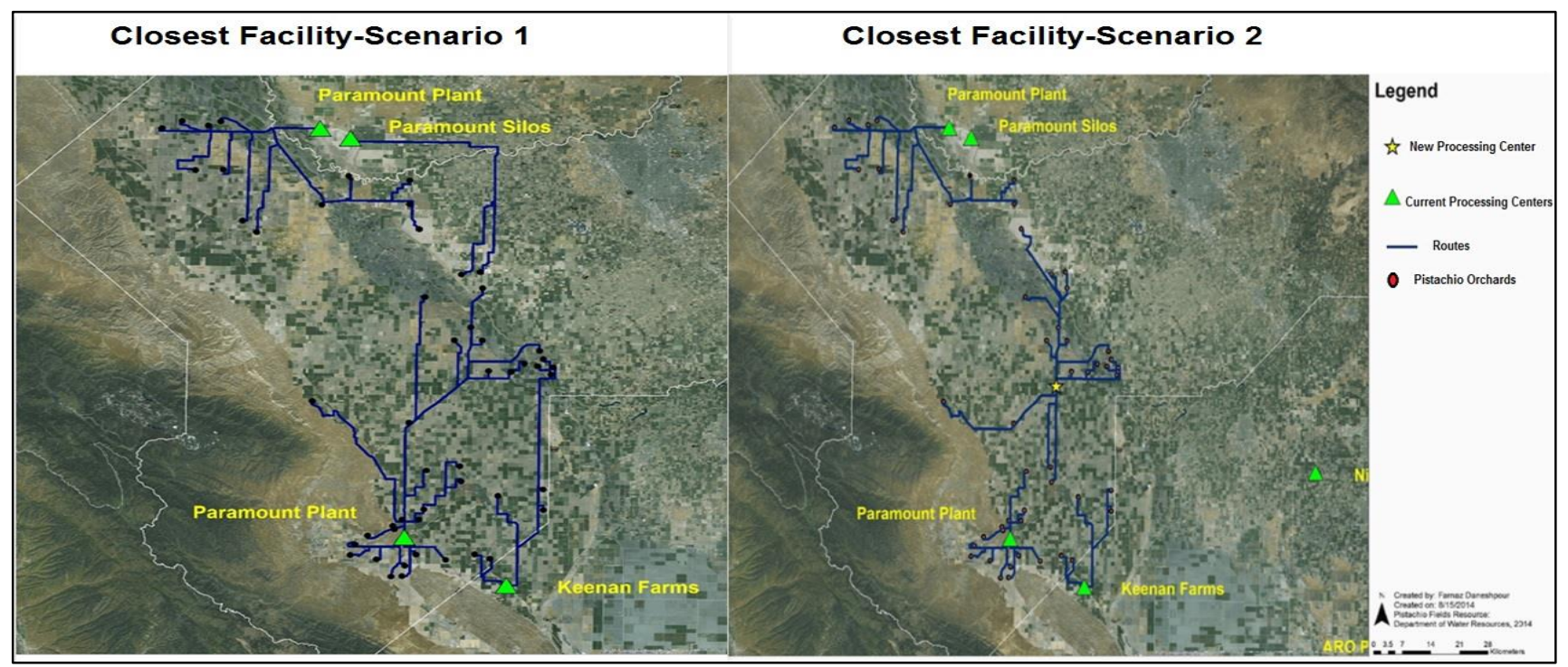

Figure 13. Comparing Closest Facility Scenario 1 and 2.

As it is shown in Table 7, all acreage, number of farms, and total production, which are allocated to each facility based on closest distance, were calculated. For example, 13 farms with a total acreage of 9,825.6 acres associated with total production of $26,358,677$ pounds are allocated to Paramount Processing center (1) in Madera County in scenario 1. However, it shows 12 farms with total acreage of 5,184.6 acres associated with total production of 13,908,377 pounds are allocated to the Paramount processing center (1) in Madera County in scenario 2. Also, in scenario 2, there is not any farm in Fresno County allocated to the Paramount Silo (2) in Madera County.

Comparing these two scenarios shows that a new center reduces total amount of acreage, production, and number of farms associated with Paramount and Keenan facilities. As a result, it is shown that the new facility center captures 20 pistachio farms, which is quite a large number in comparison to other centers. In addition, the new facility captures total acreage of 20,186 associated with 54,152,108 pounds of production. Comparing these numbers with the same ones associated with other selected facilities shows that the new center has a big potential to capture the area. Consequently, results show how locating the new center allocates a big volume of production to itself. 
Table 7. Comparing Closest Facility Scenarios 1 and 2

\begin{tabular}{|c|c|c|c|c|c|c|c|c|c|c|c|c|c|c|c|}
\hline \multirow[t]{2}{*}{$\begin{array}{l}\text { Closest } \\
\text { Facility }\end{array}$} & \multicolumn{3}{|c|}{$\begin{array}{c}\text { Paramount Processing } 1 \\
\text { (Madera) }\end{array}$} & \multicolumn{3}{|c|}{$\begin{array}{l}\text { Paramount Silo } \\
2 \text { (Madera) }\end{array}$} & \multicolumn{3}{|c|}{$\begin{array}{c}\text { Paramount Processing } \\
3 \text { (Fresno) }\end{array}$} & \multicolumn{3}{|c|}{$\begin{array}{l}\text { Keenan Farms } \\
\quad \text { (Kings) }\end{array}$} & \multicolumn{3}{|c|}{$\begin{array}{c}\text { New Processing Center } \\
\text { (Fresno) }\end{array}$} \\
\hline & Acreage & $\begin{array}{c}\# \\
\text { Farms }\end{array}$ & $\begin{array}{l}\text { Total } \\
\text { Production } \\
\text { (lb) }\end{array}$ & Acreage & $\begin{array}{c}\# \\
\text { Farms }\end{array}$ & $\begin{array}{c}\text { Total } \\
\text { Production } \\
\text { (lb) }\end{array}$ & Acreage & $\begin{array}{c}\# \\
\text { Farms }\end{array}$ & $\begin{array}{c}\text { Total } \\
\text { Production } \\
\text { (lb) }\end{array}$ & Acreage & $\begin{array}{c}\# \\
\text { Farms }\end{array}$ & $\begin{array}{c}\text { Total } \\
\text { Production } \\
\text { (lb) }\end{array}$ & Acreage & \# Farms & $\begin{array}{c}\text { Total } \\
\text { Production } \\
\text { (lb) }\end{array}$ \\
\hline $\begin{array}{c}\text { Scenario } \\
1\end{array}$ & $9,825.6$ & 13 & $26,358,677$ & 866.5 & 2 & $2,324,435$ & $20,791.1$ & 28 & $55,775,384$ & $8,413.6$ & 9 & $22,570,756$ & N/A & N/A & N/A \\
\hline $\begin{array}{c}\text { Scenario } \\
2\end{array}$ & $5,184.6$ & 12 & 13,908,377 & N/A & N/A & N/A & $9,126.6$ & 15 & $24,483,301$ & $5,399.7$ & 5 & $14,485,466$ & 20,186 & 20 & $54,152,108$ \\
\hline
\end{tabular}


In table 8 , the result of comparing two scenarios based on total distance, Co2 emissions, fuel cost, shipping time, and how much saving might be considered is shown. As a result, total distance from each farm to the processing center, for one harvesting period in scenarios 1 and 2, is 33,662.93 miles and 19,956.03 miles, respectively. Therefore, in scenario 2 , the distance is $13,706.9$ miles less than scenario 1 , in other words, there is $41 \%$ saving in distance traveled.

In addition, comparing these two scenarios shows how much would be saved in producing $\mathrm{Co} 2$, fuel cost, and transportation time. Although the difference between variables in scenarios 1 and 2 is not the same, the saving percentage, $41 \%$, is the same for all these four variables. Since, the most effective factor is the total distance for each scenario, there is a linear relationship between variables, so their percentages are the same.

When the total mile-tons for each scenario was divided by fuel efficiency 293 (ton-miles per gallon), the total number of consumed gallons is shown. Then total gallons are divided by total number of trucks or trips (1784.2) for scenarios 1 and 2. For scenario 1 and 2, the average number of gallon per truck is 1.78 and 1.05 , respectively. Consequently, the new facility center on average saved 0.73 gallons of diesel per truck or per trip (from a farm to processing center) in the harvesting season.

The comparison between two scenarios shows that allocating the new processing center to the pistachio farms would be highly beneficial. The captured volume reduces the number of traffic loads for other facilities, and can minimize mileage, Co2 emission, fuel cost, and transportation time. 
Table 8. Comparing Distance, Co2, Fuel Cost, and Travel Time in Scenarios 1 and 2 over a Harvesting Season.

\begin{tabular}{|c|c|c|c|c|}
\hline & $\begin{array}{c}\text { Distance } \\
\text { (miles) }\end{array}$ & Co2 (lb/Gal) & Fuel Cost (\$) & Time (h) \\
\hline Scenario 1 & $33,662.93$ & $71,311.05$ & $13,096.0$ & 641.19 \\
\hline Scenario 2 & $19,956.03$ & $42,274.56$ & $7,763.56$ & 380.11 \\
\hline Saving (\%) & $41 \%$ & $41 \%$ & $41 \%$ & $41 \%$ \\
\hline
\end{tabular}




\section{CHAPTER V \\ SUMMARY, CONCLUSIONS, AND RECOMMENDATIONS}

\section{Summary}

Due to increasing pistachio production, exportation, and domestic consumption in the U.S, its market is very important in the U.S, specifically in California. Consequently, its

cultivation needs more natural resources, more processing centers, and more transportation. Thus, important questions are raised about how to best manage this growth and reduce potential environmental impacts such as $\mathrm{Co} 2$ emissions and soil erosion. Accordingly, it is necessary to find the best location for facilities and allocate orchards optimally to the centers regarding minimizing shipping distance to mitigate $\mathrm{Co} 2$ emissions. Also, it is important to cultivate pistachios on ideal locations based on soil characteristics to reduce soil erosion.

For this aim, Fresno County was selected because of the importance of pistachio cultivation and availability of data. This study evaluated the current transportation situation and compared it with the case in which a new processing center is built in this county. Data analysis tools including the location allocation and closest facility network analysis tools in ArcGIS software (ESRI, 2010) were used. Both the location allocation and closest facility models considered two scenarios for the analysis. Scenario 1 provided network analysis based on just the current situation of Fresno County with existing processing facilities. Scenario 2 analyzed the network analysis with a new processing center. Therefore, in the location allocation model and closest facility model regarding scenario 2, coordinates of the new facility center which was calculated by the Center of Gravity model 
were added to the data. Using the Center of Gravity model showed that the new location of the pistachio processing center is on the west side of Fresno County close to ideal cultivation areas.

By employing ArcGIS for the analysis of optimal locations of pistachio cultivation based on the soil characteristics ( $\mathrm{pH}$ range, Sandy/Clay loam, and drainage), it was determined that 330,546 acres in Fresno county are optimal for pistachio cultivation. However, there is only 10,645 acres of pistachio farms from the total of 39,897 acres (26.7\%) located in the ideal location. From another perspective, there is only $3.22 \%$ of the ideal locations covered by pistachio cultivations, which is very negligible. If farmers cultivate their farms based on a proper knowledge about the soil characteristics, not only their farms production amount will be improved, but the natural resources deterioration such soil erosion will be minimized.

By using ArcGIS network analysis to compare the two scenarios, the results showed that the new processing center captures 20 farms and 54,152,108 lbs of production, which are quite large numbers in comparison with other current centers. In other words, building the new processing center decreases the amount of supplies to the other processing centers and reduces their production amount. Comparing the two scenarios showed that there is a $41 \%$ saving in shipping distance, $\mathrm{Co} 2$, fuel cost, and driving time in a harvesting period by allocating the new processing center to the pistachio farms. In addition, the new facility center saved 0.72 gallon of diesel per truck in the harvesting season. Moreover, the results of the sensitivity analysis suggest the same $41 \%$ of savings in shipping time, cost, and Co2 emission comparing scenario 1 and scenario 2 . Thus, the saving percentage is not sensitive to the average speed. 


\section{Conclusion}

In this study, the aim was to find the best locations for pistachio cultivation and the place for the new potential processing center in Fresno County. Moreover, the location allocation and closest facility models were compared with the current pistachio transportations from orchards to processing centers with the situation of a new processing facility.

On one hand, cultivation on soil with poor structure, low water-holding capacity, different $\mathrm{pH}$ values, and low nutrient levels causes a higher rate of soil erosion. As a result, farmers have to utilize more fertilizers and organic matter to prepare the suitable soil for cultivation (Duffy, 2012). On the other hand, the pistachio yield is improved by utilizing quality lands which have appropriate soil characteristics for pistachio cultivation. Therefore, it is beneficial for both pistachio farmers and natural resources to cultivate in the best locations.

Regarding ideal locations for the pistachio cultivation which is on the west side of Fresno County, there may be some issues. Although, these ideal areas show the best soil for the maximum pistachio production, it does not necessarily mean that farmers are able to choose them as their farms in the future. Therefore, it is possible that other crops or nuts are being cultivated in these areas such as almonds or walnuts which may be more valuable than pistachios. Also, it is possible that other crops have exactly the same soil requirements as pistachios for maximum yield.

Moreover, it is important to consider other factors affecting maximum pistachio production. Although the best soil factors were considered for this study, there may be some other soil characteristics which affect reduction in pistachio production such as 
salinity of soil. Therefore, farmers may decide to not choose those areas because the disadvantages outweigh the advantages. Another issue is water restrictions which is very important for cultivation. Without access to enough water for production, farmers are unable to have maximum yields in the long run.

Regarding the calculated saving percentage, this study showed there is $41 \%$ savings for shipping distance, $\mathrm{Co} 2$ emissions, fuel cost, and transit time which might be valuable for decision makers to consider. When less mileage is driven by trucks, fewer gallons of gas are burned, therefore both fuel cost and $\mathrm{Co} 2$ emissions are reduced. Reducing $\mathrm{Co} 2$ emissions should be considered because it is one of the most pollutant greenhouse gasses causing climate change. Therefore, with $41 \%$ savings in Co 2 emissions, building the new processing center might be very beneficial for decreasing environmental impact in the long run. In addition, by driving less mileage, the amount of traffic is decreased which potentially would reduce the number of road accidents. Moreover, by saving $41 \%$ in shipping time, the pistachios' transportation will be faster and this may have a considerable effect on the quality of pistachios; for example, reducing spoilage time.

Although there is $41 \%$ saving in the mentioned variables, it does not necessarily mean that building a new processing center would be a good idea. Since this study does not investigate the cost of establishing and operating a new processing center, it is not logical to say that this idea is beneficial just based on these savings. Thus, lots of various factors and cost structures must be considered to have an optimal decision.

There are two consequences for processing centers when they are operating at less than a full production capacity. On one hand, since a company produces less than its production capacity, it does not have as much profit as when it is producing under its full 
production capacity, while it is bearing the same fixed production cost as the full capacity production scenario. Consequently, the company's incomes may not cover its cost in the long run, which causes the company's bankruptcy.

Therefore, the new processing center might cause an economic loss for other companies affected by it. On the other hand, when the production load is less, a facility center can meet more orders on time. Thus, it can have higher level of the production quality, which is more important than the amount of production.

\section{Recommendation}

This research suggests the need for more detailed pistachio orchards' ownership information, transportation schedule, and truck costs from farmers to provide decision makers with better analytical results to optimize the transportation situation. Moreover, it is suggested that in order to make a better decision regarding the beneficiary of the new center, a stronger economic correlation between a cost-benefit analysis and an estimation of the exact production capacity of the current and the new processing centers is required.

Regarding facilities in the Central Valley, it is suggested to investigate more detailed information that can help to make a better decision to optimize the current transportation situation; for example, facility capacities, demand limitations, and buying and shipping contracts. By obtaining detailed information, it can be used in the location allocation model as a way to provide more accurate and precise results.

Since this study identified the location of the new facility based on the current orchards, it would be a good idea to find the best facility location based on possible future orchards converging to optimal cultivation areas following soil characteristics. Therefore, 
exact estimations of future information such as pistachio acreages, yield per acre, and number of orchards need to be considered.

This study found the location of the new facility center by the Center of Gravity model based on all of the pistachio orchards as one group; however, it would be prudent to determine the best facility location based on each ranch. For example, it is suggested to divide all pistachio orchards in different groups based on a specific location. Next, by considering them as different ranches, the location of a new facility for each ranch is defined.

This study has not investigated what currently is in the ideal soil locations, and has only found the optimal location and does not have any constraints for feasible locations other than pistachios. Therefore, more investigation and analyses on this issue can help find out about current usage of the ideal soil locations and consequently provide farmers with a better decision. Also, it is recommended to extend the same analyses and procedures for California as a whole. In addition, there is a capability of utilizing the same methodology for other kinds of crops and nuts, for which data are available in each part of the world.

Since this study was conducted based on the trucks' speed, weight, and direction assumptions, it would be beneficial to combine the trucks' exact weights in both directions from farms to facilities and vice versa. Therefore, both directions distances would be considered for the analyses and results will be more close to reality. 


\section{List of References}

Administrative Committee for Pistachios. (2013). Pistachio Bearing Acreage, Production and Yield per Acre. Administrative Committee for Pistachios Processors' Producer Delivery Reports and Acreage Surveys. Retrieved June 2, 2014. http://www.acpistachios.org/statistics.shtml

Administrative Committee for Pistachios. (2014). Pistachios Processors (Hullers/Dryers). http://www.acpistachios.org/grower-resources.shtml

Aghazadeh, S. (2004). Improving logistics operations across the food industry supply chain. International Journal of Contemporary Hospitality Management, 16(4), 263268

Alston, J. M., Sumner, D. A., Brunke, H., \& Acquaye, A. K. (2005). Economic consequences of mandated grading and food safety assurance: ex ante analysis of the federal marketing order for California pistachios. Giannini Foundation of Agricultural Economics, University of California.

Angeles, R. (2010). The Significance of RFID in Green Supply Chain Initiatives. In Proceedings of ITAIS 2010 Conference.

Arifin, S. (2013). Location allocation problem using genetic algorithm and simulated annealing. A case study based on school in Enschede.

Aronsson, H., \& Brodin, M. H. (2006). The environmental impact of changing logistics structures. The International Journal of Logistics Structures. The International Journal of Logistics Management, 17(3), 394e415. 
Bantham, A., \& Oldham, C. (2003). Creating value through traceability solutions. Food Origins. Illinois, USA.

Beede, R. H., Kallsen, C. E., Ferguson, L., Holtz, B. A., Klonsky, K. M., \& De Moura, L. R. (2008). Sample costs to establish and produce pistachios. University of California Cooperative Extension. San Joaquin Valley.

Boriss, H. (2005). Commodity Profile: Pistachios. UC Agricultural Issues Center. Updated November 2013 by Diane Huntrods, AgMRC, Iowa State University. Retrieved May 13, 2014. http://www.agmrc.org/commodities_products/nuts/pistachio-profile/

Bosona, T. G., \& Gebresenbet, G. (2011). Cluster building and logistics network integration of local food supply chain. Biosystems engineering, 108(4), 293-302.

Bosona, T., Nordmark, I., Gebresenbet, G., \& Ljungberg, D. (2013). GIS-Based Analysis of Integrated Food Distribution Network in Local Food Supply Chain.International Journal of Business and Management, 8(17), p13.

Brimer, R. C. (1995). Logistics networking: A consideration of the components essential to an integrated logistics support network. Logistics Information Management, $8(4), 811$.

Buzby, J. C., \& Hyman, J. (2012). Total and per capita value of food loss in the United States. Food Policy, 37(5), 561-570.

California Pistachio Research Board, (2013). Pistachio Processors - Hulling and Drying, Retrieved April 10, 2014. http://www.calpistachioresearch.org/IndustryLinks.html 
CDFA (2013), California Department of Food and Agriculture, Agricultural Statistical Overview, California Agricultural Statistics Review 2013-2014. California Department of Food and Agriculture.

Chaiken, J. M., Walker, W. E., \& Ignall, E. (1976). Deployment Methodology for Fire Departments: How Station Locations and Dispatching Practices Can be Analyzed and Improved: Prepared for the Office of Policy Development and Research, Department of Housing and Urban Development. Rand.

Chuang, P. T. (2002). A QFD approach for distribution's location model. International Journal of Quality \& Reliability Management, 19(8/9), 1037-1054.

Church, R. L. (2002). Geographical information systems and location science. Computers \& Operations Research, 29(6), 541-562.

CLECAT’s Best Practice Guide to save energy and reduce emissions (2010). http://www.clecat.org/dmdocuments/sr005osust101201clecatsustlogbpg2nded.pdf Couceiro, J. F., Guerrero, J., Gijón, M. C., Pérez-López, D., Moriana, A., \& Rodriguez, M. (2013). El cultivo del pistacho. Mundi-Prensa, Madrid.

Craiga, A. J., Blancob, E. E., \& Sheffi, Y. (2012). Estimating the Co2 Intensity of Intermodal Freight Transportation. Transportation Research Part D: Transport and Environment, 24, 2-34.

CRFG. (1997). California Rare Fruit Growers. Pistachio Fruit Facts. Retrieved May 5, 2014, from http://www.crfg.org/pubs/ff/pistachio.html

Davis, S. C., Diegel, S. W., \& Boundy, R. G. (2013). Vehicle Technologies Market Report. US Department of Energy, Vehicle Technologies Office, Oak Ridge National Laboratory, Oak Ridge. 
Demirkiran, A. R., \& Cengiz, M. C. (2013). Effects of different organic materials and chemical fertilizers on nutrition of pistachio (Pistacia vera L.) in organic arboriculture. African Journal of Biotechnology, 9(38), 6320-6328.

Dreher, M. L. (2012). Pistachio nuts: composition and potential health benefits. Nutrition reviews, 70(4), 234-240.

Duffy, M. (2012). Value of soil erosion to the land owner. Agr Decision Maker, File A175 (August 2012). Iowa State University, Extension and Outreach.

Easa, S., \& Chan, Y. (2000). Urban planning and development applications of GIS. ASCE.

EIA, (2013). Annual energy outlook 2013. Transportation sector energy consumption, US Energy Information Administration, Washington, DC.

EIA, (2014). Annual Energy Outlook 2014. Energy-Related Co2 Emissions. U.S. Energy Information Administration. Washington, D.C.

EIA, (2014). Annual Energy Outlook 2014. Technical Report. U.S. Energy Information Administration. Washington, D.C.

EIA, (2014). FREQUENTLY ASKED QUESTIONS. U.S. Energy Information Administration. Washington, D.C. Retrieved June 15, 2014 http://www.eia.gov/tools/faqs/faq.cfm?id=307\&t=11

EIA, (2014). Weekly Retail on Highway Diesel Prices, 2000-2014. U.S. Energy Information Administration. Washington, D.C. Internet accessed June 15, 2014. http://www.eia.gov/petroleum/fueldiesel/

ESRI Roads. (2014). Network Analyst. http://www.arcgis.com/home/item.html?id=0f4ae38e76b241609057286f6b34f597 
ESRI (2010). ArcGIS desktop help, ESRI. New York, USA: GIS Software Corporate. http://services.arcgisonline.com/arcgis/services

FAO, (2014). FAOSTAT-Crop Production. Food and Agriculture Organization.

Retrieved June 5, 2014, from http://faostat.fao.org.

FAO, (2014). FAOSTAT-Trade. Food and Agriculture Organization. Retrieved June 5, 2014, from http://faostat.fao.org.

Federal Register, (2010). Light-Duty Vehicle Greenhouse Gasses Emission Standards and Corporate Average Fuel Economy Standards; Final Rule, page 25,330 (PDF).

Federalimentare, (2012), http://www.federalimentare.it/m_banche_dati.asp

Ferguson, L., Polito, V., \& Kallsen, C. (2005). The pistachio tree; botany and physiology and factors that affect yield. Pistachio production manual, 4th ed. Davis, CA, USA, University of California Fruit \& Nut Research Information Center, 31-39.

Flowmap-Lab. (27-1-2011). Flowmap Home page [Web page from website]. Available: http://flowmap.geog.uu.nl/

Forsman, S., \& Paananen, J. (2010). Local food systems: explorative findings from Finland MTT agrifood research Finland Economic Research. Luutnantintie, 13. FIN- 00410 Helsinki.

Franzese, O., \& Davidson, D. (2011). Effect of weight and roadway grade on the fuel economy of class-8 freight trucks. Oak Ridge National Laboratory, Tennessee, USA.

Fresno Department of Agriculture, (2012). Fresno County Annual Agricultural Crop and Livestock Report, http://www.co.fresno.ca.us/WorkArea/DownloadAsset.aspx?id=55145 
Fuente, D., \& Lozano, J. (1998). Determining warehouse number and location in Spain by cluster analysis. International Journal of Physical Distribution \& Logistics Management, 28(1), 68-79.

Gebresenbet, G., \& Bosona, T. (2011). Logistics and Supply Chains in Agriculture and Food. Pathways to Supply Chain Excellence.

Gebresenbet, G., Nordmark, I., Bosona, T., \& Ljungberg, D. (2011). Potential for optimized food deliveries in and around Uppsala city, Sweden. Journal of transport geography, 19(6), 1456-1464.

Ghose, M. K., Dikshit, A. K., \& Sharma, S. K. (2006). A GIS based transportation model for solid waste disposal-A case study on Asansol municipality. Waste Management, 26(11), 1287-1293.

Gong, D., Gen, M., Xu, W., \& Yamazaki, G. (1995). Hybrid evolutionary method for obstacle location-allocation. Computers \& Industrial Engineering, 29(1), 525-530.

Good Agricultural Practices Manual Guidelines for California Pistachio Growers 2009 Edition, California Pistachio Research Board, Growing Pistachios in California. Retrieved June 2, 2014. http://fruitsandnuts.ucdavis.edu/pages/pistachio/ Hernandez, T., \& Bennison, D. (2000). The art and science of retail location decisions. International Journal of Retail and Distribution Management, 28(8), 357e367

Hormaza, J. I., \& Wünsch, A. (2007). Pistachio. In Fruits and nuts (pp. 243-251). Springer Berlin Heidelberg.

Jamshidi, M. (2009). Median location problem. In Facility Location (pp. 177-191). 
Jiangxia, W., Yunfeng, L., \& Kejun, L. (2011, May). Spatial optimum allocation of small watershed land resource. In Water Resource and Environmental Protection (ISWREP), 2011 International Symposium on, Vol. 2, pp. 996-999.

Karim, K. MH., \& Vardan, E., U., E., (2003). Global Pistachio Production and Marketing Challenge. University of S \& B, Iran.

Kizilgoz, I., Kizilkaya, R., Acar, I., Kaptan, H., (2001). Nutrient contents of pistachio trees (Pistacia vera L.) growing in district of Sanliurfa and the relationship between their microelement deficiency and some soil properties. Cahiers Options Méditerranéennes 56, 47-52.

Koshteh, K., \& Urutyan, V. (2005). Global pistachio production and marketing challenges. Indian Journal of Economics and Business, 4(1).

Koukoulakis, P., Chatzissavvidis, C., Papadopoulos, A., \& Pontikis, D. (2013). Interactions between leaf macronutrients, micronutrients and soil properties in pistachio (Pistacia vera L.) orchards. Acta Botanica Croatica, 72(2), 295-310.

Li, H., Yu, L., \& Cheng, E. W. (2005). A GIS-based site selection system for real estate projects. Construction Innovation: Information, Process, Management, 5(4), 231241.

Li, X., \& Yeh, A. G. O. (2005). Integration of genetic algorithms and GIS for optimal location search. International Journal of Geographical Information Science, 19(5), 581-601.

Lindeskov, C. K. (2002). Ambulance Allocation Using GIS (Doctoral dissertation, Technical University of Denmark, DTU, DK-2800 Kgs. Lyngby, Denmark). 
Litman, T. (2011). Smart Transportation Emission Reduction Strategies-Identifying Truly Optimal Ways to Conserve Energy And Reduce Emissions.

Ljungberg, D., Gebresenbet, G., \& Aradom, S. (2007). Logistics chain of animal transport and abattoir operations. Biosystems Engineering, 96(2), 267e277.

Ludin, M., \& Nazri, A. (2008). Integrating GIS and gravity model in evaluating location suitability of hypermarkets.

Manzini, R., \& Accorsi, R. (2013). The new conceptual framework for food supply chain assessment. Journal of Food Engineering, 115(2), 251-263.

Massey, S. L. (2011). Fire Station Site Selection in Rural Areas: A Case Study of Dickinson County, Kansas (Doctoral dissertation, Northwest Missouri State University).

Meyer, E. W. (2011). Performing Location Allocation Measures with a GIS for Fire Stations in Toledo, Ohio (Doctoral dissertation, University of Toledo).

Min, H., Jayaraman, V., \& Srivastava, R. (1998). Combined location-routing problems: A synthesis and future research directions. European Journal of Operational Research, 108(1), 115.

Mitchell, P.S. (1971). Efficient Allocation of Fire Department Resources - Part 1, Fire Technology 7 (3): $237-242$.

Morgan, C. (2007). Supply network performance measurement: future challenges. The International Journal of Logistics Management, 18(2), 255e273.

Murray, A. T. (2003). Site placement uncertainty in location analysis. Computers, Environment and Urban Systems, 27(2), 205-221. 
Myers, R. J. (2009). One-hundred years of pH. Journal of Chemical Education, 87(1), 3032.

NACo, (2013).Find a County. National Association of Counties. Retrieved August 15, 2014. Http://www.naco.org/counties/pages/findacounty.aspx.

Nath, S. S., Bolte, J. P., Ross, L. G., \& Aguilar-Manjarrez, J. (2000). Applications of geographical information systems (GIS) for spatial decision support in aquaculture. Aquacultural Engineering, 23(1), 233-278.

Onay, A. (2005). Pistachio (Pistacia vera L.). In Protocol for Somatic Embryogenesis in Woody Plants (pp. 289-300). Springer Netherlands.

Oum, T. H., \& Park, J. (2003). Multinational firms' location preference for regional distribution centers: focus on the Northeast Asian region. Transportation Research Part E, 40, 101e121.

Panichelli, L., \& Gnansounou, E. (2008). GIS-based approach for defining bioenergy facilities location: A case study in Northern Spain based on marginal delivery costs and resources competition between facilities. Biomass and Bioenergy, 32(4), 289-300.

Peterson, D. (2009). An Interactive GIS Map of Autism Resources in Missouri.

Pistachio Processors/Suppliers 2012-2013, Retrieved April 25, 2014. http://www.americanpistachios.org/about-apg/suppliers-processors

Pitaksringkarn, L., \& Taylor, M. A. (2005). Grouping Genetic Alogirhtm in GIS: A Facility Location Modelling. Journal of the Eastern Asia Society for Transportation Studies, 6, 2908-2920. 
Razavi, S. (2005). Pistachio production, Iran vs. the world. In IV International Symposium on Pistachios and Almonds 726 (pp. 689-694).

Revelle, C., \& Snyder, S. (1995). Integrated fire and ambulance siting: A deterministic model. Socio-Economic Planning Sciences, 29(4), 261-271.

Ritter, J., \& Eng, P., (2012). Soil Erosion — Causes and Effects. (12)-053, October 2012.

Rosenthal, E. (2008). Environmental cost of shipping groceries around the world. The New York Times, 26.

Russell, R. S., \& Taylor, B. W. (2009). Operations management along the supply chain (6th ed). John Wiley and Sons (Asia) Pte Ltd.

Sakbaeva, Z., Acosta-Martínez, V., Moore-Kucera, J., Hudnall, W., \& Nuridin, K. (2012). Interactions of soil order and land use management on soil properties in the Kukart watershed, Kyrgyzstan. Applied and Environmental Soil Science, 2012.

Salin, V. (1998). Information technology in agri-food supply chains. The International Food and Agribusiness Management Review, 1(3), 329-334.

Sandhu, J., \& Chandrasekhar, T. (2010). ArcGIS network analyst tutorial.

Sasaki, S., Comber, A. J., Suzuki, H., \& Brunsdon, C. (2010). Using genetic algorithms to optimize current and future health planning-the example of ambulance locations. International journal of health geographics, 9(1), 4.

Scaparra, M. P., \& Scutellà, M. G. (2001). Facilities, locations, customers: building blocks of location models. A survey.

Schietzelt, T. H., \& Densham, P. J. (2003). Location-allocation in GIS. Advanced spatial analysis: the CASA book of GIS. 
Schleupner, C., \& Schneider, U. A. (2013). Allocation of European wetland restoration options for systematic conservation planning. Land Use Policy,30(1), 604-614.

Serra, D., \& Marianov, V. (1998). The P median problem in a changing network: the case of Barcelona. Location Science, 6(1), 383-394.

Soysal, M., Bloemhof-Ruwaard, J. M., \& van der Vorst, J. G. A. J. (2014). Modelling food logistics networks with emission considerations: The case of an international beef supply chain. International Journal of Production Economics, 152, 57-70.

Stevenson, S., \& Pirog, R. (2007). Values-based food supply chains: strategies for agrifood enterprises-of-the-middle.

Tootelian, D. H. (2011). Pistachio Power. A Report on an Industry of Investment, Impact, and Return. Westren Pistachio Association Economic Impact Study.

University of California Statewide IPM Project. (2006). UC Pest Management Guidelines, Pistachios. University of California, Davis CA.

USCB, (2011). American Community Survey, United States Census Bureau. American Community Survey 5-Year Estimates. American FactFinder. Retrieved June 5, 2014.

USCB, (2013). State \& County QuickFacts. United States Census Bureau. Retrieved August 15, 2014. Http://quickfacts.census.gov/qfd/states/06000.html.

USDA, ERS (2013). Fruit and Tree Nuts Outlook. United States Department of Agriculture. Economic Research Service report FTS-354. Retrieved April 30. http://www.ers.usda.gov/media/970458/fts354. pdf

USDA, ERS (2013). Pistachios: Supply and utilization (shelled basis), 1980/81 to date. United States Department of Agriculture. Economic Research Service. 
USDA, FAS (2013). United States Department of Agriculture, Foreign Agricultural Service. Tree Nuts: Pistachios World Markets and Trade, 2012-2013. http://usda.mannlib.cornell.edu/usda/fas/treenutwm//2010s/2013/treenutwm-0215-2013.pdf

USDA, FAS (2013). United States Department of Agriculture, Foreign Agricultural Service. Production, Supply and Distribution Online. http://www.fas.usda.gov/psdonline/psdHome.aspx

USDA, FAS (2013). United States Department of Agriculture, Foreign Agricultural Service. World Market and Trade Reports 2014. http://apps.fas.usda.gov/psdonline/psdDataPublications.aspx

USDA, FAS (2013). United States Department of Agriculture, Foreign Agricultural Service. Tree Nuts: Pistachios World Markets and Trade 2013.

USDA, FAS (2014). Foreign Agricultural Service (FAS).Global Agricultural Trade System (GATS), Retrieved June 7, 2014. http://apps.fas.usda.gov/gats/default.aspx

USDA, FAS (2014). United States Department of Agriculture, Foreign Agricultural Service. Pistachios: World Markets and Trade, 2013-2014. http://apps.fas.usda.gov/psdonline/circulars/TreeNuts.pdf

USDA, NASS (2012), 2012 State Agriculture Overview California, United States Department of Agriculture. National Agricultural Statistics Service www.nass.usda.gov/Quick_Stats/Ag_Overview/stateOverview.php?state=CALIF ORNIA 
USDA, NASS (2013). United States Department of Agriculture. National Agriculture Statistic Service (NASS), http://quickstats.nass.usda.gov/data/printable/1440C969-3BEC-38A1-BC30662463263147

USDA, NASS (2013).The National Agricultural Statistics Service, Retrieved May 9, 2014. http://quickstats.nass.usda.gov/\#5D0278CE-20F2-3668-B2BAEF701DB7F489

USDA, NASS (2014). California Pistachio Preliminary Price. United States Department of Agriculture, National Agricultural Statistics Service, Retrieved May 7, 2014, from http://www.nass.usda.gov/Statistics_by_State/California/index.asp

USDA, NASS (2014). National Agricultural Statistics Service, Cropland Data Layer for the United States. http://www.nass.usda.gov/research/Cropland/SARS1a.htm

USDA, NASS (2014). Non-citrus Fruits and Nuts. National Agricultural Statistical Service.USDA. Retrieved May 23, 2014. http://usda.mannlib.cornell.edu/MannUsda/viewDocumentInfo.do?documentID=1 113

U.S. Geological Survey Fact Sheet, (2011). Science Education Handout, March 2011 page 137-97.

Wakeland, W., Cholette, S., \& Venkat, K. (2012). Food transportation issues and reducing carbon footprint. In Green Technologies in Food Production and Processing (pp. 211-236). Springer US.

Wang, F. (2010). Quantitative methods and applications in GIS. CRC Press. 
Wang, X., Yu, S., \& Huang, G. H. (2004). Land allocation based on integrated GISoptimization modeling at a watershed level. Landscape and Urban Planning, 66(2), 61-74.

Web Soil Survey. (2014). http://websoilsurvey.sc.egov.usda.gov/App/HomePage.htm

Wood, S., \& Browne, S. (2007). Convenience store location planning and forecasting-a practical research agenda. International Journal of Retail \& Distribution Management, 35(4), 233-255.

Zhang, F., Johnson, D. M., \& Sutherland, J. W. (2011). A GIS-based method for identifying the optimal location for a facility to convert forest biomass to biofuel. Biomass and Bioenergy, 35(9), 3951-3961.

Zheng, Z., Saghaian, S., \& Reed, M. (2012). Factors Affecting the Export Demand for US Pistachios. International Food and Agribusiness Management Review, 15(3), 139-154. 


\section{Appendices}

\section{A. Central Valley Pistachio Processing Centers Addresses}

\begin{tabular}{|l|l|}
\hline Name & Address \\
\hline Paramount Farms & 39840 S El Dorado Ave., Coalinga, CA 93210 \\
\hline Paramount Farms & 10429 King Rd., Lost Hills, CA 93249 \\
\hline Paramount Farms & 13646 Highway 33, Lost Hills, CA 93249 \\
\hline Paramount Farms & 10302 Ave. 7 1/2 Firebaugh, CA 93622 \\
\hline $\begin{array}{l}\text { Paramount Farms Silos } \\
\text { Setton Farms }\end{array}$ & 9370 Road 13, Firebaugh, CA 93622 \\
\hline $\begin{array}{l}\text { Keenan Farms } \\
\text { Primex Farms }\end{array}$ & 31510 Plymouth Ave., Kettleman City, CA 93239 \\
\hline $\begin{array}{l}\text { ARO Pistachio } \\
\text { Nichols Farms }\end{array}$ & 16070 Wildwood Rd., Wasco, CA 93280 Ave. 88, Terra Bella, CA 93270 \\
Monarch Nut & 13762 First Ave., Hanford, CA 93230 \\
\hline
\end{tabular}




\section{B. Center of Gravity Technique Calculation Table for all of Pistachio Orchards}

\begin{tabular}{|c|c|c|c|c|c|c|c|c|}
\hline FID & Shape & SHAPE_Leng & SHAPE_Area & $\mathrm{x}$ & $Y$ & Acre & Yield lb/Acre & Total Production (lb) \\
\hline 1 & Polygon & 3131.597443 & 612426.6218 & 1903400 & 639476 & 151.333914 & $2,682.66$ & 405,977 \\
\hline 2 & Polygon & 4819.26879 & 1273062.545 & 1909980 & 624991 & 314.580606 & $2,682.66$ & 843,913 \\
\hline 3 & Polygon & 4814.269193 & 1280828.089 & 1891150 & 586271 & 316.499514 & $2,682.66$ & 849,061 \\
\hline 5 & Polygon & 5663.355944 & 497302.0408 & 1889500 & 593291 & 122.88601 & $2,682.66$ & 329,661 \\
\hline 6 & Polygon & 3172.713387 & 629093.9967 & 1890700 & 595153 & 155.452512 & $2,682.66$ & 417,026 \\
\hline 7 & Polygon & 4805.758546 & 1277882.691 & 1900000 & 602475 & 315.77169 & $2,682.66$ & 847,108 \\
\hline 10 & Polygon & 4194.191715 & 1032103.598 & 1893360 & 595136 & 255.038353 & $2,682.66$ & 684,181 \\
\hline 11 & Polygon & 9614.203612 & 4516768.676 & 1894160 & 597081 & 1116.117847 & $2,682.66$ & $2,994,160$ \\
\hline 12 & Polygon & 6374.621784 & 2539305.516 & 1897610 & 587426 & 627.476058 & $2,682.66$ & $1,683,300$ \\
\hline 13 & Polygon & 8122.019887 & 3943709.657 & 1890710 & 584278 & 974.511879 & $2,682.66$ & $2,614,280$ \\
\hline 14 & Polygon & 4360.473236 & 848493.7094 & 1888960 & 584199 & 209.667362 & $2,682.66$ & 562,466 \\
\hline 15 & Polygon & 18251.07263 & 10771739.91 & 1886660 & 587549 & 2661.7549 & $2,682.66$ & $7,140,580$ \\
\hline 20 & Polygon & 20121.2872 & 16334606.06 & 1904350 & 623629 & 4036.369062 & $2,682.66$ & $10,828,200$ \\
\hline 21 & Polygon & 6180.195208 & 1817829.393 & 1907970 & 623455 & 449.195426 & $2,682.66$ & $1,205,040$ \\
\hline 22 & Polygon & 16478.21028 & 8990567.256 & 1912420 & 627466 & 2221.617551 & $2,682.66$ & $5,959,840$ \\
\hline 23 & Polygon & 6027.635676 & 1840717.927 & 1898960 & 629538 & 454.851306 & $2,682.66$ & $1,220,210$ \\
\hline 24 & Polygon & 9511.04325 & 4137394.44 & 1901550 & 632001 & 1022.372431 & $2,682.66$ & $2,742,680$ \\
\hline 25 & Polygon & 7882.154563 & 2203482.899 & 1894370 & 637792 & 544.492482 & $2,682.66$ & $1,460,690$ \\
\hline 26 & Polygon & 7003.138547 & 2059983.978 & 1892880 & 588407 & 509.033127 & $2,682.66$ & $1,365,560$ \\
\hline 27 & Polygon & 8090.090514 & 2104534.323 & 1899810 & 605344 & 520.041757 & $2,682.66$ & $1,395,100$ \\
\hline 28 & Polygon & 13008.04999 & 3349978.461 & 1876610 & 617837 & 827.797706 & $2,682.66$ & $2,220,700$ \\
\hline 29 & Polygon & 3013.745618 & 563302.2471 & 1860220 & 670668 & 139.195017 & $2,682.66$ & 373,413 \\
\hline 30 & Polygon & 4235.76545 & 938030.1377 & 1856090 & 671540 & 231.792295 & $2,682.66$ & 621,820 \\
\hline 39 & Polygon & 7062.717311 & 1271824.856 & 1865610 & 652426 & 314.274766 & $2,682.66$ & 843,092 \\
\hline 40 & Polygon & 12917.45919 & 6107801.585 & 1858180 & 662129 & 1509.270641 & $2,682.66$ & $4,048,860$ \\
\hline 41 & Polygon & 6485.051246 & 1333566.218 & 1862560 & 662205 & 329.531389 & $2,682.66$ & 884,021 \\
\hline 42 & Polygon & 7766.695551 & 2368248.923 & 1900060 & 642114 & 585.207054 & $2,682.66$ & $1,569,910$ \\
\hline 43 & Polygon & 6360.462384 & 1138218.14 & 1903030 & 642555 & 281.259828 & $2,682.66$ & 754,525 \\
\hline 44 & Polygon & 12403.16756 & 4455046.365 & 1912960 & 625888 & 1100.865931 & $2,682.66$ & $2,953,250$ \\
\hline 45 & Polygon & 5669.30528 & 1261542.274 & 1904520 & 587631 & 311.733885 & $2,682.66$ & 836,276 \\
\hline 46 & Polygon & 6414.690964 & 2571531.905 & 1912960 & 596987 & 635.439372 & $2,682.66$ & $1,704,670$ \\
\hline 47 & Polygon & 9102.257984 & 2925711.133 & 1914210 & 622922 & 722.958966 & $2,682.66$ & $1,939,450$ \\
\hline 48 & Polygon & 9175.174797 & 2718096.126 & 1914520 & 624285 & 671.65618 & $2,682.66$ & $1,801,830$ \\
\hline 49 & Polygon & 7340.580024 & 2097995.076 & 1912020 & 624530 & 518.425874 & $2,682.66$ & $1,390,760$ \\
\hline 50 & Polygon & 14593.08097 & 6805409.507 & 1902160 & 588477 & 1681.653312 & $2,682.66$ & $4,511,300$ \\
\hline 51 & Polygon & 12394.61889 & 5270116.232 & 1905810 & 599672 & 1302.274082 & $2,682.66$ & $3,493,560$ \\
\hline 52 & Polygon & 11478.22278 & 5943074.594 & 1912940 & 600902 & 1468.565715 & $2,682.66$ & $3,939,660$ \\
\hline
\end{tabular}

